\title{
Non-CPAP therapies in obstructive sleep
} \section{apnoea}

\author{
W.J. Randerath*, J. Verbraecken*, S. Andreas, G. Bettega, A. Boudewyns, \\ E. Hamans, F. Jalbert, J.R. Paoli, B. Sanner, I. Smith, B.A. Stuck, L. Lacassagne, \\ M. Marklund, J.T. Maurer, J.L. Pepin, A. Valipour, T. Verse and I. Fietze, \\ the European Respiratory Society task force on non-CPAP therapies in \\ sleep apnoea
}

ABSTRACT: In view of the high prevalence and the relevant impairment of patients with obstructive sleep apnoea syndrome (OSAS) lots of methods are offered which promise definitive cures for or relevant improvement of OSAS.

This report summarises the efficacy of alternative treatment options in OSAS.

An interdisciplinary European Respiratory Society task force evaluated the scientific literature according to the standards of evidence-based medicine.

Evidence supports the use of mandibular advancement devices in mild to moderate OSAS. Maxillomandibular osteotomy seems to be as efficient as continuous positive airway pressure (CPAP) in patients who refuse conservative treatment. Distraction osteogenesis is usefully applied in congenital micrognathia or midface hypoplasia. There is a trend towards improvment after weight reduction. Positional therapy is clearly inferior to CPAP and long-term compliance is poor. Drugs, nasal dilators and apnoea triggered muscle stimulation cannot be recommended as effective treatments of OSAS at the moment. Nasal surgery, radiofrequency tonsil reduction, tongue base surgery, uvulopalatal flap, laser midline glossectomy, tongue suspension and genioglossus advancement cannot be recommended as single interventions. Uvulopalatopharyngoplasty, pillar implants and hyoid suspension should only be considered in selected patients and potential benefits should be weighed against the risk of long-term side-effects. Multilevel surgery is only a salvage procedure for OSA patients.

KEYWORDS: Mandibular advancement devices, maxillomandibular osteotomy, multilevel surgery, neuromuscular stimulation, uvulopalatopharyngoplasty, weight reduction

ince the first description of their application in the early 1980 s by SulLivan et al. [1], continuous positive airway pressure (CPAP) and the more recent developments of automatic positive airway pressure and bilevel therapy have become the standard treatment of obstructive sleep apnoea syndrome (OSAS) [1]. Positive airway pressure has proven to improve symptoms, normalise the risk of traffic and workplace accidents, and reduce the elevated sympathetic activity and risk for cardiovascular morbidities, especially arterial hypertension. Most recently, it has been shown that CPAP normalises mortality in patients with severe OSAS $[2,3]$.
However, despite the efficacy of CPAP, many patients suffer from local side-effects at the nose or face, or discomfort due to the mask. Moreover, CPAP does not allow for a permanent resolution of respiratory disturbances during sleep, but only suppresses them while using the devices. Therefore, many patients look for more comfortable or curative treatment options. Both conservative and surgical alternative therapeutic approaches have been described. However, there is a need to discuss the scientific evidence for these therapies.

Thus, the European Respiratory Society funded a task force with the aim of screening the scientific
AFFILIATIONS

For the authors' affiliation details, please refer to the Acknowledgements section. *W.J. Randerath and J. Verbraecken contributed equally to this work.

\section{CORRESPONDENCE}

W.J. Randerath

Institute for Pneumology at the University Witten/Herdecke,

Clinic for Pneumology and Allergology, Centre of Sleep Medicine and Respiratory Care, Bethanien Hospital Aufderhöherstraße 169-175 42699 Solingen

Germany

E-mail: randerath@klinik-

bethanien.de

Received:

June 292010

Accepted after revision:

Dec 252010 
literature on non-positive-pressure therapies, evaluating the studies according to the criteria of the evidence-based medicine, and giving recommendations for use in OSAS patients. The treatment of central sleep apnoea and periodic breathing was not in the focus of this work. The results of the task force will be presented in this report and in more detail in two following articles on conservative treatment options and two on surgical approaches.

\section{METHODS}

The members of the task force performed individualised literature searches for each topic area using electronic databases, hand searches of relevant papers, and screening of reference lists up to January 1, 2009. In addition, in May 2010 the authors screened the literature for more recent papers which might change the conclusions and recommendations relevantly. Reviews, guidelines and case reports were excluded. Studies were included only if data of at least three subjects were available and if sleep testing was performed using polygraphy (cardiorespiratory monitoring) or polysomnography. Studies were evaluated according to the Oxford Centre for Evidencebased Medicine's levels of evidence (tables 1 and 2) [4]. The level of recommendation (A, B, C or D) is given of the end of each section. All other tables are available in the online supplementary material (tables e1-e38).

Changes reported are significant at the $p<0.05$ level, unless indicated otherwise. If required, statistical analysis was performed to assess pre- versus postoperative differences in outcome parameters using either Mann-Whitney U- or paired t-test, as appropriate.

\section{RECOMMENDATIONS OF THE TASK FORCE}

1) There is a trend to worsening but not spontaneous cure of sleep disordered breathing (C).

2) Weight reduction is associated with a trend to improvement in breathing pattern, quality of sleep and daytime sleepiness, and is recommended to reduce this important risk factor $(\mathrm{C})$.

3) Positional therapy can yield moderate reductions in apnoeahypopnoea index (AHI) (younger patients, low AHI and less obese) but is clearly inferior to CPAP and, therefore, cannot be recommended except in carefully selected patients. Long-term compliance with positional therapy is poor (C).

\section{TABLE 1 Evidence levels}

1a Systematic analysis (systematic review) of RCTs with homogenous results

1b Particular RCT with limited dispersion

1c Therapy, before its introduction all patients died

2a Systematic review of cohort studies with homogenous results

2b Particular cohort studies or RCT of lower quality

2c "Outcomes" research; ecological studies

3a Systematic review of case-control studies with homogenous results

3b Particular case-control study

4 Case studies and cohort studies or case-control studies of limited quality

5 Expert opinions

RCT: randomised controlled trial.
4) Apnoea triggered muscle stimulation cannot be recommended as an effective treatment of OSAS at the moment (negative recommendation $\mathrm{C}$ ). Although tongue muscle training improves snoring, it is not efficacious in the treatment of sleep apnoea in general (negative recommendation B).

5) Mandibular advancement devices (MADs) reduce sleep apnoeas and subjective daytime sleepiness, improve quality of life compared with control treatments, and are recommended in the treatment of patients with mild to moderate obstructive sleep apnoea (OSA) (A). There is emerging evidence on the beneficial cardiovascular effects of MADs. However, tongueretaining devices (TRDs) cannot be recommended (C).

6) Drug therapy is not recommended as treatment for OSA (most drugs C, for mirtazapine and protryptilline B).

7) Nasal dilators are not recommended for reducing snoring, or for improving sleep disordered breathing or sleep architecture in OSA (D).

8) Nasal surgery as a single intervention cannot be recommended for treatment of OSA (negative recommendation C).

9) Intranasal corticosteroids improve mild to moderate OSA in children with co-existing rhinitis and/or upper airway obstruction due to adenotonsillar hypertrophy (B). They may also show some benefit with respect to both symptoms and some sleep parameters. Intranasal corticosteroids can be recommended as concomitant therapy in these situations.

10) Tonsillectomy as a single therapy can be recommended for treatment of OSA in the presence of tonsillar hypertrophy in adults (C). Adenotonsillectomy can be recommended in the presence of adenotonsillar hypertrophy associated with paediatric OSA (C). Radiofrequency tonsil reduction is not recommended as a single procedure for the treatment of OSA (negative recommendation D).

11) Uvulopalatopharyngoplasty (UPPP) is a single-level surgical procedure effective only in selected patients with obstruction limited to the oropharyngeal area. When proposing UPPP, potential benefits should be weighed against the risk of frequent long-term side-effects, such as velopharyngeal insufficiency, dry throat and abnormal swallowing. UPPP cannot be recommended except in carefully selected patients (C).

12) Laser assisted uvulopalatoplasty has not demonstrated any significant effect, either on OSA severity or in symptoms or quality of life domains, and is not recommended (negative recommendation $\mathrm{B})$.

13) Due to insufficient evidence, radiofrequency surgery of the soft palate may only be considered in patients with mild disease refusing or not requiring $\mathrm{CPAP}$, as long as the

\section{TABLE 2 Grades of recommendation}

A Consistent level 1 studies
B Consistent level 2 or 3 studies or extrapolations of level 1 studies
C Level 4 studies or extrapolations of level 2 or 3 studies
D Level 5 or inconsistent studies of other levels

A Consistent level 1 studies

C Level 4 studies or extrapolations of level 2 or 3 studies

D Level 5 or inconsistent studies of other levels 
individual anatomy appears suitable. It cannot be recommended except in carefully selected patients (C).

14) Uvulopalatal flap as a single intervention can only be recommended in selected cases for treatment of OSA (C). Studies investigating the uvulopalatal flap with tonsillectomy for OSA show a significant improvement of the severity of OSA and quality of life, and this combined intervention can be recommended in selected patients (B).

15) Pillar ${ }_{\circledast}$ implants may be considered in patients with mild to moderate OSA, who are suitable with regard to their overall physical condition (not or only moderately obese, no or small tonsils and no sign of retrolingual obstruction), if conservative approaches are not accepted by the patient. Pillar implants cannot be recommended except in carefully selected patients (B).

16) Due to insufficient evidence, radiofrequency surgery of the tongue base as an isolated or combined procedure cannot be recommended and may only be considered in selected patients intolerant to conservative treatment as long as the overall condition appears suitable (non- or only moderately obese patients with retrolingual obstruction) (C).

17) Due to insufficient evidence, hyoid suspension cannot be recommended and may only be considered in carefully selected patients (C) and may be combined with other procedures in multilevel surgery (MLS) (B).

18) Procedures such as laser midline glossectomy and tongue suspension (Repose ${ }^{\circledR}$ ) have a small role as a single treatment option for obese patients with moderate to severe OSA and cannot be recommended. There are at present no data about their role in patients with mild disease (negative recommendation $\mathrm{C}$ ).

19) Genioglossus advancement cannot be recommended as a single procedure for the surgical treatment of OSA (C).

20) Maxillomandibular advancement (MMA) seems to be as efficient as CPAP in patients with OSA who refuse conservative treatment, particularly in a young OSA population without excessive body mass index (BMI) or other comorbidities, and is recommended in this circumstance (B).

21) Distraction osteogenesis (DOG) can be recommended in congenital micrognathia or midface hypoplasia (mandibular lengthening: B; midface advancement: C).

22) MLS cannot be recommended as a substitute for CPAP but as a salvage procedure for OSA patients in whom CPAP and other conservative therapies have failed. Surgical success of MLS for OSA is often unpredictable and less effective than CPAP (C).

\section{CONSERVATIVE NON-CPAP TREATMENT OPTIONS The natural course of OSA}

\section{Rationale}

In the face of the high prevalence and the socioeconomic burden of OSAS the question arises if all patients have to be treated immediately after diagnosis or if spontaneous normalisation might be expected at least in a portion of patients.

\section{Search strategy}

Databases individually searched: PubMed and Medline. Keyword combinations: sleep apnoea AND progression OR natural course OR prognosis OR evolution OR long-term follow up. Of the selected papers, 24 studies reported data on the natural course of the disease.

\section{Overview of the evidence}

There is a lack of knowledge on the age of onset and the course of sleep apnoea. It is widely accepted that snoring typically begins between the ages of 30 and $40 \mathrm{yrs}$, and that the incidence of sleep apnoea increases between ages 40 and 65 yrs. These data, however, do not reveal the progression of the disorder with respect to its extent: neither concerning the AHI, nor clinical symptoms, nor comorbidity.

Only a small number of studies [3,5-11] have investigated the natural course of sleep apnoea with respect to cardiovascular risk and mortality. The studies cited here monitored those patients who refused to undergo appropriate therapy. A small number of studies has been performed investigating the course of the disease in patients with low AHI. No long-term followup studies have been performed on sleepiness, the primary symptom of OSA.

The present state of knowledge on this matter considering only those follow-up studies with more than 20 participants can be summarised as follows: TISHLER et al. [12] studied healthy persons (i.e. AHI <5) and found a 5 -yr incidence of $7.5 \%$ for OSA with an AHI $>15$, and of $\sim 16 \%$ with AHI $>10$. The incidence of sleep apnoea was independent of age, sex, BMI, waist/hip ratio and serum cholesterol level. Interestingly, the influence of BMI diminished with increasing age. The Wisconsin Sleep Cohort Study and the Cleveland Family Study revealed a significant increase over the time in AHI, especially among male, obese, older and snoring patients [13, 14]. Studies in the elderly revealed a progression of OSA in correlation with age over the long term, but not with BMI [15]. The Sleep Heart Health Study found that the increase of the AHI upon an increase of the BMI over a 5-yr period was greater than a reduction of AHI under weight loss. The influence of body weight was significantly greater among males than among females [16]. In addition, PEPPARD et al. [17] reported a six-fold increase in odds ratio for the development of OSA, as accompanied by a $10 \%$ increase in body weight within 4 yrs.

There are conflicting results on the modulation of the severity of OSAS over time. While several investigators showed an increase of severity in mild to moderate sleep apnoea patients over time independently of the BMI, others failed to demonstrate deterioration of upper airway resistance syndromes or found improvements of respiratory disturbances $[5,18-24]$.

\section{Conclusions and recommendations}

There is a lack of population-based studies on the spontaneous course of OSA. However, both increasing incidence and progression of AHI have been demonstrated for patients with mild to moderate OSA between the ages of 40 and $60 \mathrm{yrs}$, even independently of possible change in BMI. In contrast, a similar evolution has not been proven among the elderly and among those patients with higher initial AHI. In all age groups, however, the primary risk factor for progression and elevated 
incidence is the increase of body weight. An additional factor is evidently male sex.

At least in mild sleep-related breathing disorders future research should address the influence of concomitant diseases and their therapy on the course of sleep apnoea, the significance of snoring with respect to the development from snoring to sleep apnoea, development of cardiovascular risks in snorers and sleep apnoea (table e1).

The presented data show a trend to worsening of sleep disordered breathing over time. Most studies are retrospective and observational (case series). Based on these data, we state that a spontaneous improvement cannot be expected (C).

\section{Weight reduction}

Rationale

Obstructive sleep-related breathing disorders are caused by pharyngeal and/or laryngeal collapse. Pharyngeal fat deposits lead to a decrease in pharyngeal patency and underline the risk factor of obesity [25, 26]. Weight reduction will lead to a decrease in critical closing pressure $\left(P_{\text {crit }}\right)$, and consequently decreases the severity of OSA [27].

\section{Search criteria}

Databases individually searched: PubMed and Medline. Keyword combinations: sleep apnoea syndromes AND weight reduction. Of the 47 selected papers, three studies reported data on the mechanisms of action of weight reduction (change in $P_{\text {crit, }}$ change in pharyngeal cross-sectional area, change in respiratory mechanics).

\section{Overview of the evidence}

51 studies were identified, reporting on the effect of weight reduction in adults, 25 on diet instructions, 24 on surgical intervention (one study evaluated both) and three on pharmaceutical weight reduction. One study performed in extremely overweight adolescents was also included [28]. Six studies were published by the same study group. 17 studies on diet instruction intervention were case series, or evidence level 4 . Surgical treatment (gastric banding, gastroplasty or gastric bypass) was evaluated in 24 studies, which were also all case series. Pharmaceutical weight reduction was reported in two case series in the same population and in one randomised controlled trial. Only studies with sibutramine were performed. 10 studies were based on polygraphy (seven diet studies, three surgery studies, one both). Seven of these polygraphic studies were performed in Finland. Weight changes have been calculated partly as change in $\mathrm{kg}$, partly as change in BMI, partly as change in excess body weight (EBW) (and expressed as percentage EBW) or as change in percentage of ideal body weight (IBW). Therefore, an overall change in body weight related to change in AHI cannot be expressed (tables e2 and e3).

In the diet intervention studies, mean BMI reduction of $4.7 \pm 2.5 \mathrm{~kg} \cdot \mathrm{m}^{-2}$ was accompanied by a decrease of the AHI by $21 \pm 13 \mathrm{~h}^{-1}$ (44\%) (table e2). 246 patients (39\%) showed a partial improvement in AHI, while 145 patients (23\%) were cured of OSA. In the surgery intervention studies, change in BMI was between $10-24.4 \mathrm{~kg} \cdot \mathrm{m}^{-2}$. Three studies reported reduction of the percentage of IBW between 26.4 and $82 \%$
IBW (17-73\%). The AHI decreased by $44 \pm 22 \mathrm{~h}^{-1}$ (77\%) (table e3) [29-31]. 94 patients (34.2\%) showed a partial improvement in AHI, while 177 patients $(64.4 \%)$ were cured of OSA. In the pharmaceutical intervention studies, change in BMI was between 1.8 and $2.6 \mathrm{~kg} \cdot \mathrm{m}^{-2}$, accompanied by a decrease of the AHI between 2.8 and $16.3 \mathrm{~h}^{-1}$ (7-35.6\%) (table e4) [32-34].

An increase in deep sleep could be observed from +4 to $+17 \%$, while other studies found no change in deep sleep, or even a small decrease [35]. In all but one study, rapid eye movement (REM) sleep increased by $1-10 \%$. An improvement of sleepiness based on self-assessment scales was reported after diet and behavioural management, and after surgery, and after pharmaceutical weight reduction [31-41]. In one study an unchanged mean multiple sleep latency test (MSLT) was reported [41]. The evaluated study period was not always indicated; the longest study period was 7 yrs [40].

\section{Conclusions and recommendations}

Presented data show, under a weight reduction (BMI 0.2$24.4 \mathrm{~kg} \cdot \mathrm{m}^{-2}$ ), a trend to improvement in breathing pattern, an increase in REM sleep (1-10\%) and deep sleep ( 0 to $+17 \%)$, and a decrease in daytime sleepiness. Most studies are retrospective and observational (case series), and while randomised controlled trials have been published in recent years, they report inconsistent results and, therefore, none provide highlevel evidence. Weight reduction is recommended to reduce the important underlying risk factor of obesity. Most available studies have level 4 (C).

\section{Positional therapy}

\section{Rationale}

The number and duration of respiratory disturbances depend on body position and sleep stage [42-46]. The cross-section and the closing pressures of the pharynx differ according to body position and stage of sleep [47-49]. Ventilatory drive is dependent on body position. Thus, there is ample evidence suggesting a positive effect of a lateral position during sleep. Using the definition of positional OSA as a supine AHI of at least twice that in the lateral position, a prevalence of $\sim 50 \%$ is reported [50].

\section{Search criteria}

Databases individually searched: PubMed and Medline. Keyword combinations: sleep apnoea AND positional therapy. A recent review on medical therapy of OSA was screened. 27 of the 39 articles found were excluded, mostly because they did not contain data on the efficacy of positional therapy in the treatment of OSA (table e5).

\section{Overview of the evidence}

Clinical experience and observational studies suggest that the patients exhibiting a large decrease in $\mathrm{AHI}$ in the lateral position compared with the supine position tend to have a lower AHI, to be younger and to be less obese [44, 51]. Accordingly, patients with a clear improvement of the AHI with positional therapy tended to be younger, to have a lower $\mathrm{AHI}$ and to be less obese $[42,52,53]$. It is not possible to extract from the data whether AHI, age or obesity is the best predictor of treatment success. It is more likely that these parameters are mutually interrelated. 
Different devices such as tennis balls, vests, positional alarms, verbal instruction and pillows are used to avoid the supine position [53-58]. There are no data comparing the different devices, with the exception that verbal instructions seem to be less effective than a positional alarm [42, 59].

A number of short-term studies demonstrate significant but moderate effects on AHI. However, most studies were uncontrolled and small [52-54, 56, 57, 60]. More importantly, even in a subset of patients with clear positional sleep apnoea, effectiveness was limited. Two uncontrolled studies suggested some improvement of sleep stages or daytime symptoms with positional therapy $[57,58]$.

One study had a clinically meaningful follow-up period of 2 yrs [56]. Only $29 \%$ used the positional vest in this study after 2 yrs [56]. In a randomised crossover comparison with CPAP, positional therapy (elevation of head and shoulder) was clearly inferior in terms of the AHI [61].

\section{Conclusions and recommendations}

Patients with a clear improvement of the AHI with positional therapy tend to be younger, to have a lower AHI, and to be less obese. Positional therapy can yield moderate reductions in AHI but is clearly inferior to CPAP. Long-term compliance with positional therapy is poor. If positional therapy is used, sleep studies are recommended to document individual success. Long-term compliance has to be secured by follow-up studies.

Recommendation: positional therapy is not recommended for the treatment of OSA, except in carefully selected patients. If positional therapy is used, sleep studies have to be performed to document individual success. Long-term compliance has to be secured by follow-up studies (C).

\section{Intraoral protrusion devices}

\section{Mandibular advancement devices}

Rationale

MADs reposition the lower jaw forwards and downwards during sleep. The treatment aims to widen the upper airways in order to improve the upper airway patency, and reduce snoring and obstructive sleep apnoeas.

\section{Search strategy}

Databases individually searched: PubMed and Medline. Keyword combinations: sleep apnoea syndromes AND orthodontic appliances; functional or removable, activator appliances or mandibular advancement, sleep apnoea AND oral appliances, mandibular advancement devices, mandibular repositioning appliances, mandibular advancement splints or mandibular repositioning splints were individually used. Out of 79 articles in total, 29 were excluded because the topic was covered in the randomised controlled trials or the aims were not directly related to the efficacy of the device. 27 randomised controlled trials about treatment effects from MADs and five randomised controlled trials in particular topics were found (table e6). In addition, 18 other clinical trials that highlighted particular aspects of MAD treatment were identified.

\section{Overview of the evidence}

The 27 randomised controlled trials evaluated the effects of MADs compared with placebo treatment [62-70], CPAP
$[66,69,71-77]$ or between appliance designs [78-87]. Two studies reported long-term results after 2 and 4 yrs of treatment, respectively $[86,88]$. The sample sizes in these studies ranged from 19 to 114 patients. The patients were overweight or obese (mean BMI $26-33 \mathrm{~kg} \cdot \mathrm{m}^{-2}$ ).

MADs have been shown to widen primarily the lateral parts of the upper airway [89] and to reduce pharyngeal collapsibility [90]. MAD treatment reduced sleep apnoeas compared with placebo in all studies [62-66, 68-70]. Treatment success with MAD, defined as an $\mathrm{AHI}$ of $<5$, was found in $19-75 \%$ of the patients and an index of $<10$ was reported in $30-94 \%$ of the patients [63-68, 70-79, 81, 82, 84, 85, 87, 91, 92]. Sleep apnoeas increased slightly and some patients discontinued treatment in the longer term [86, 88]. Milder sleep apnoea, supinedependent sleep apnoeas, female sex and less obesity have been related to treatment success with MADs [63, 65, 70, 76, 82, $92,93]$. CPAP reduced sleep apnoeas more efficiently or gave a higher success rate in all studies [66, 69, 71-77].

Subjective daytime sleepiness decreased from MAD treatment compared with placebo according to many short-term studies $[62,64,66,68,70]$, although control treatment may also give positive effects $[64,69]$. The effect on sleepiness was usually similar between CPAP and MADs [66, 72, 74-77], but CPAP may produce a better outcome than $\operatorname{MAD}[69,71,73]$. Snoring is more effectively controlled with CPAP than with MADs [72], but there is a better effect from MADs than placebo [63, 64]. Persistent snoring during MAD treatment may be a sign of a poor apnoea control [71]. Promising effects on blood pressure, cardiac function, endothelial function, markers of oxidative stress and simulated driving performance have been reported from MADs [66, 69, 84, 94-99].

Titratable custom-made MADs have been used in the majority of the efficacy studies. Comparison between device designs indicated that there are only minor differences in treatment effects between custom-made devices [78, 80, 83, 84 ], while a prefabricated device was less effective [85]. The degree of mandibular advancement is crucial, since a nonadvanced device is ineffective on sleep apnoeas $[62,65,70]$ and may even increase the apnoea frequency [62]. A titration procedure is therefore recommended to achieve optimal results [87, 91, 100, 101].

Initial side-effects, such as jaw discomfort, tooth tenderness, excessive salivation and/or temporary occlusal changes, were reported in slightly more than half of the patients $[63,65,69$, $71-74,78]$, and more frequently from MAD than from a control plate [64]. After $1 \mathrm{yr}, 76 \%$ of the patients continued treatment [92] and 65\% were still using their devices after 4 yrs [88]. Compliance monitors have been introduced [102]. Compliance with MADs has been reported to be higher than with CPAP $[66,77]$ and MADs are often preferred by the patients $[71,72$, $74,75,77]$.

\section{Conclusions and recommendations}

MADs are recommended for the treatment of patients with mild to moderate OSA (A) and in patients who do not tolerate CPAP. MADs reduce sleep apnoeas and subjective daytime sleepiness and improve quality of life compared with control treatments. There is emerging evidence on beneficial cardiovascular effects from MADs. CPAP more effectively reduces 
sleep apnoeas, while the positive effects on symptoms and health are more similar between these treatments. Patients generally prefer MADs over CPAP. The device should be custom-made, evaluated and advance the mandible at least $50 \%$ of maximum protrusion. A titration procedure is essential. Re-evaluation with a new sleep apnoea recording is necessary, since the improvement of OSA symptoms is an imprecise indicator of treatment success. This is particularly important in patients with a more severe disease and in patients with concomitant health problems. Follow-up should be performed regularly over the long term.

\section{Tongue retaining devices}

Rationale

TRDs are designed to produce a suction of the tongue into an anterior bulb, move the tongue forwards and widen the upper airway dimensions during sleep, in order to reduce obstructive sleep apnoeas and snoring.

\section{Search strategy}

Databases individually searched: PubMed and Medline. Keyword combinations: sleep apnoea AND tongue retaining device or tongue stabilizing device were individually used for searches in PubMed. In total, three randomised controlled trials $[59,103,104]$ and three other trials with small sample sizes were found (table e7) [105-107].

\section{Overview of the evidence}

The three randomised controlled trials [59, 103, 104] evaluated the effects of TRDs on sleep apnoeas and symptoms and analysed predictors (table e7). One randomised controlled trial showed significant effects from TRD on sleep apnoeas compared with a control device in patients with mild to moderate sleep apnoea [103]. A comparison between a tongue stabilising device and MAD in another randomised controlled trial showed a similar apnoea reduction from the two devices, although the patients preferred MADs [104]. TRD was compared with posture alarm and positional treatment in 60 patients with positional dependency and moderate OSA. TRD reduced sleep apnoeas in the supine position and gave some benefit for patients who continued to sleep in that position [59]. One of the clinical trials showed an effect of TRD on oxygen desaturations [106], while the other two studies did not show any reduction in sleep apnoeas from this type of treatment in small samples of moderate to severe sleep apnoea patients [105, 107].

\section{Conclusions and recommendations}

TRDs are not recommended for patients with OSA. They can be used in selected patients with mild to moderate OSA (C), when other treatments have failed or are not possible. These patients may have a trial with this device, provided that the treatment effect is monitored and the patients are strictly followed up. A few studies show reductions in sleep apnoeas from TRDs, although symptomatic effects are mainly unknown and compliance might be a limitation.

\section{Training of the upper airway muscles and hypoglossus nerve stimulation}

Rationale

The obstruction of the upper airways is accompanied by diminished neuromuscular activity of the dilating muscles
[108]. In healthy subjects, these muscles stabilise the pharyngeal airway. In order to counterbalance the collapsible forces, the upper airway muscles have to contract more intensively [109]. The genioglossus muscle is one of the most important dilators. It pushes forward the tongue and enlarges the cross-sectional area of the upper airways. Its activity is increased in OSAS during wakefulness, which has been proposed to be a compensatory mechanism [110, 111]. Based on these findings the question arose of whether direct or indirect stimulation of the upper airway muscles optimise the dilating forces and increases the width of the upper airways. Present developments focus mainly on hypoglossus nerve stimulation. Electrical stimulation is performed during sleep to counteract respiratory disturbances whenever they appear. Conversely, training procedures have been developed aiming at improving the altered upper airway muscles. These training procedures are performed during wakefulness.

\section{Search criteria}

Databases individually searched: PubMed. Keyword combinations: neurostimulation OR electrical stimulation OR upper airway muscles OR genioglossus stimulation OR hypoglossus nerve stimulation AND sleep apnoea syndrome. 28 studies were found, of which 13 were included in the further evaluation. The other studies did not focus on the electrical stimulation of the upper airway muscles, but on physiological or pathophysiological aspects, effects of MADs or drugs on the upper airway muscles or surgical or anaesthesiological aspects (table e8).

\section{Overview of the evidence}

Acute efficacy of electrical stimulation on upper airway patency Stimulation of the upper airway muscles with surface and intraneural electrodes has proven to reduce the resistance of the upper airways both in healthy persons and patients with OSAS [27, 112-118]. The stimulation of the genioglossus muscle most effectively reduces resistance and the critical pressure $P_{\text {crit }}[113,115,116]$.

\section{Efficacy of apnoea triggered neurostimulation in clinical use}

There are conflicting results on the clinical efficacy of apnoea triggered neurostimulation. Intraneural stimulation of the hypoglossus nerve and transcutaneous electrical stimulation of the genioglossus muscle showed significant improvements of respiratory disturbances and sleep parameters without adverse effects [112, 119]. In contrast, other groups failed to find an enlargement of the upper airways by transcutaneous or intramuscular stimulation during wakefulness or sleep. However, undesirable contractions of the platysma or tongue were observed and arousals were induced [114, 116, 120, 121]. OLIVEN and co-workers $[115,116]$ studied the critical pharyngeal pressure under intraneural hypoglossus and intramuscular and surface genioglossus stimulation and demonstrated that the patency of the upper airways depends more on the effective stimulation of the genioglossus muscles.

\section{Tongue muscle training by electrical stimulation}

Electrical stimulation has proven to be effective in the rehabilitation of skeletal muscles after injury. It activates motor units in healthy muscles, which cannot be reached voluntarily. Based on these findings the question arises if training of the 
pharyngeal muscles, especially the genioglossus muscle, during the daytime might improve the respiratory disturbances during sleep. Preliminary results of case studies and one cohort showed improvements of the AHI, daytime sleepiness and snoring [122, 123]. The only placebo-controlled double-blind study on tongue muscle training found an improvement of snoring but no significant reduction of AHI [124].

\section{Oropharyngeal exercise}

In addition to electrical stimulation of the upper airway muscles, the question of whether exercises may improve symptoms of OSAS has been studied. PUHAN et al. [125] showed a reduction, but not normalisation, of the AHI after didgeridoo playing. More recently, GuIMARAES et al. [126] randomised 31 patients with moderate OSAS to 3 months of oropharyngeal exercises or sham therapy. They found significant, but limited, reduction of the AHI. Moreover, snoring, daytime sleepiness, neck circumference and self-assessment questionnaires demonstrated improvements. It is unclear which of the several exercises was most relevant for the treatment effect.

\section{Conclusions and recommendations}

Apnoea triggered muscle stimulation cannot be recommended as an effective treatment of OSAS at the moment (C). Although oropharyngeal exercise has shown limited effects on snoring and respiratory disturbances, its role is not clear at the moment and, therefore, it cannot be recommended (B).

\section{Drug therapy}

Neuromediator modulators

\section{Rationale}

Although there may be a predisposing airway abnormality, it is changes in respiratory drive, airway tone or surface forces that cause airway closure during sleep. Pharmaceutical agents might reduce sleep apnoea by increasing respiratory drive, changing sleep structure (in particular suppressing REM sleep), increasing upper airway muscle tone, changing respiratory and cardiovascular reflexes that may perpetuate apnoeas and reducing surface forces that encourage closure of the upper airway.

\section{Search strategy}

Databases individually searched: PubMed and Medline. Keyword combinations: Sleep apnoea/apnoea (drug* or pharmacological and (treatment $\left.{ }^{*}\right)$ ) or progesterone or progestogen or medroxy* or "tricyclic anti depressant" $t^{*}$ or protriptyline or amitriptyline or imipramine or ssri or fluoxetine or clonidine or modafinil or stimulant* or Buspirone or doxapram or dopram or naloxone or narcan or "opiod antagonist*" or nicotin* or "ACE inhibitor" or ACE-inhibitor* or cilazapril or captopril or enalapril or fosinopril or imidapril or lisinopril or perindopril or quinapril or ramipril or trandolapril or "anti hypertensive $e^{* \prime \prime}$ or anti-hypertensive* or antihypertensive* or baclofen or mirtazapine or steroid* or *steroid or fluticasone.

Reports on snorers or subjects with predominantly central apnoeas were excluded. Even with these filters a large number of low quality studies were identified. For nearly all of the drugs that have been trialled in the past 20 yrs there is at least one randomised controlled trial and so uncontrolled studies and review articles were excluded.

\section{Overview of the evidence}

25 studies (24 papers) were identified, reporting the effects of 24 drugs and recruiting between them 413 subjects. Due to small size, a lack of detail in reporting the methods, in particular randomisation, and incomplete data, few of the studies scored higher than $2 \mathrm{~b}$ for level of evidence. Three studies included protriptyline, their results were subjected to meta-analysis and scored as 1a (table e9) [127].

Protriptyline is a tricyclic antidepressant that inhibits re-uptake of serotonin and noradrenaline. It might reduce the proportion of REM sleep in people with REM predominant OSA and increase the airway tone mediated by serotonin acting on the genioglossus via the hypoglossal nerve. However, there was no impact on respiratory indices but there was an improvement in daytime symptoms in two out of three trials, presumably due to a nonspecific alerting effect of the drug. Adverse sideeffects, such as dry mouth and urinary symptoms, were commonly reported. Protriptyline does not have any place in the routine treatment of OSA [128-130].

Specific serotonin re-uptake inhibitors such as paroxetine have been investigated as possible treatments for OSA. In a small single night study, paroxetine $40 \mathrm{mg}$ had no impact on AHI compared to placebo with severe OSA [131]. By contrast, in a study with 6-week treatment arms paroxetine $20 \mathrm{mg}$ was shown to reduce AHI to 23.3 compared with 30.3 for placebo. There was a positive impact on respiratory events in non-REM sleep but no effect in REM sleep, and no improvement in daytime symptoms [132].

Mirtazapine is another drug with antidepressant activity that acts as an agonist at some serotonin receptors and can also increase serotonin secretion. This might increase sertonergic tone to the hypoglossal nerve, which could be particularly helpful during REM sleep. Reductions in the AHI were reported in one study [133] but could not be reproduced in two multicentre trials, while many participants reported sideeffects of sleepiness and weight gain [134]. The drug cannot be recommended for use in OSA.

Cholinergic agonists have been investigated as possible treatments for OSA. In a single night study 10 subjects had an AHI of 41 on physostigmine compared with 54 on placebo [135]. The greatest impact was on apnoeas during REM sleep and there was an inverse relationship with BMI, such that slimmer subjects had a greater fall in AHI. The drug was given intravenously, making it impractical for home use. There have been no studies with oral cholinergic agents.

Acetazolamide inhibits carbonic anhydrase, producing a metabolic acidosis that increases ventilatory drive. It was shown to reduce the $\mathrm{AHI}$ in a study of 10 subjects but there was no positive impact on daytime symptoms after 1 week of treatment [130]. The subjects who had responded best to the drug were offered a more prolonged trial of treatment but only one could tolerate it in the long term. It has no role in the routine management of OSA.

In a single night study with 10 subjects, phosphocholinamin was given as a topical nasal lubricant administered twice overnight which resulted in an AHI of 14 compared with 24 with placebo [136]. In view of the duration of the study it is not 
known whether this might improve daytime symptoms but the drug was not recommended for long-term use due to anxiety about aspiration causing lipoid pneumonia. There are no published studies of any other candidate substances.

Among the other drugs that have been trialled, naltrexone, theophylline and aminophylline have been shown to reduce the number of respiratory events overnight but this was at the expense of sleep continuity and total sleep time, which makes them unsuitable agents for the treatment of OSA. Omeprazole has been said to reduce the frequency of attacks of apnoea in subjects who had both OSA and gastro-oesophageal reflux disease, but no sleep studies were performed on treatment and the attacks may well have been episodes of laryngospasm due to acid reflux, not episodes of OSA. Medroxyprogesterone, doxapram, clonidine, mibefradil, cilazapril, buspirone, ondansetron and sabeluzole have all been investigated and none has been shown to reduce the frequency of respiratory events in people with OSA or to improve daytime symptoms.

\section{Conclusions and recommendations}

At the present time there is no evidence that any drug is likely to benefit an unselected patient with OSA. Small studies have reported positive effects of certain agents on short-term outcomes. Longer studies with measures of symptomatic responses of cholinergic agents and upper airway lubricants are supported by the results of single night studies already published. It is likely that better characterisation of the predominant mechanisms of OSA in individual patients will lead to better results and this also needs further study. Drug therapy is not recommended as treatment for OSA (most drugs C; for mirtazapine and protryptilline B).

\section{Nasal steroids}

Rationale

A particularly frequent cause of nasal obstruction is allergic rhinitis, either seasonal or perennial. There are a number of reports suggesting worsening of subjective sleep quality and quality of life measures in both adults and children with allergic and perennial rhinitis [137]. Vice versa, CANOvA et al. [138] demonstrated an increased prevalence of perennial allergic rhinitis in patients with OSA (11\%) compared to case controls $(2.3 \%)$. In addition to the obstructing effects of allergic rhinitis, inflammation of the nasal mucosa may contribute to the development of adenotonsillar hypertrophy, one of the most frequently observed abnormalities in children with OSA. Intranasal corticosteroids are commonly used to treat rhinitis. A recent Cochrane review on intranasal corticosteroids showed significant efficacy of intranasal corticosteroids in improving nasal obstruction symptoms and in reducing adenoid size [139]. Consequently, this may influence the anatomic component by decreasing upper airway resistance at the nasal, adenoidal, and/or tonsillar levels. Therefore, topical nasal steroids may influence sleep apnoea severity both in children and adults.

\section{Search criteria}

Databases individually searched: PubMed and Medline. Keyword combinations: sleep apnoea and intranasal corticosteroids, sleep apnoea and inhaled corticosteroids, sleep apnoea and intranasal steroids, sleep apnoea and corticosteroids, nasal steroids and sleep apnoea, sleep apnoea and fluticasone, sleep apnoea and triamcinolone, sleep apnoea and budesonide, OSAS and corticosteroids.

Overview of the evidence

We identified only one single-centre study with a small sample size that investigated the effects of intranasal corticosteroid application for 4 weeks on polysomnographically diagnosed sleep parameters in adult patients with moderate OSA and Coexisting (perennial or seasonal) rhinitis [140]. There was a modest but significant decrease in $\mathrm{AHI}$ and an improvement in nasal airflow resistance; however, there were no significant improvements in oxygenation indices, sleep quality or snoring noise.

Five studies with a total of 136 children (age range 1-14 yrs) with mild to moderate OSA were identified. Two studies were conducted as open clinical trials without a control group, one study investigated the effects of budesonide and montelukast, using a case control design, and two studies were conducted as prospective, randomised, placebo-controlled trials. Most of the children included in these reports had evidence of co-existing rhinitis with or without adenotonsillar hypertrophy. All included reports observed significant treatment-associated improvements in the AHI (mean pre-treatment AHI range 3.7-11 versus treatment-associated mean AHI range 0.3-6). Three reports furthermore showed significant improvements in oxygenation indices and two studies demonstrated improved sleep quality. The data are, however, inconsistent with respect to sleep architecture and adenoidal size (table e10) [140-145].

\section{Conclusions and recommendations}

Intranasal steroids, as a single intervention, are not recommended for treatment of adult OSAS (C). Intranasal steroids are recommended for childhood OSAS in the presence of COexisting rhinitis and/or upper airway obstruction due to adenotonsillar hypertrophy (B).

\section{Nasal dilators}

Rationale

The nasal vestibule is a major site of resistance to airflow in healthy subjects. A high nasal resistance may increase snoring. Activation of the alae nasi and alar retraction reduce resistance to airflow and improve ventilation. Nasal dilators might improve sleep and breathing by widening the nostrils. They are fitted to exert a dilating force on the nasal valves by means of its elasticity.

\section{Search strategy}

Databases individually searched: PubMed and Medline. Literature search using the terms obstructive sleep apnoea AND nasal dilator (no limits) was performed. Original studies published in English before April 2010 were included. In addition, the reference list of the included trials was evaluated. In total, 14 studies (two randomised controlled trials and 12 other clinical trials) could be identified, published between 1988 and 2005.

\section{Overview of evidence}

Nasal dilation increases nasal cross section by $14-25 \%$ and is associated with a distinctive and sustained reduction in nasal resistance and the oral fraction of ventilation during sleep 
[146]. External nasal dilators are well tolerated [147]. They were able to reduce the maximum snoring intensity in one study [148], but in another study snoring was not influenced at all [149]. Sleep architecture remains almost unchanged in patients with habitual snoring [147, 149] and is improved slightly in patients with OSA [146]. OSA severity was reduced in one study with 10 patients with OSA and nasal obstruction [146], but not in another study with 30 patients with OSA [150], and in a study with 18 patients with upper airway resistance syndrome there was no additional effect on sleep disordered breathing [151]. It is possible that there are parameters predicting the efficacy of the devices, such as hyperplasia or hypertrophy of the lower turbinates, septal deviation, allergic rhinitis, no or only minor pharyngeal obstruction, or age $<55$ yrs (table e11) [152].

Internal nasal dilation reduces nasal resistance by $31-65 \%$ [153, 154] and thereby improves the airflow [45]. Devices have a weak effect on snoring in patients without nasal pathology [155], even in populations with different external nose structures (Caucasians and Japanese) [156], but their use resulted in a substantial decrease in snoring noise in patients with habitual snoring and/or OSA [157]. The devices have only little or no effect on the number of apnoeas, hypopnoeas and oxygen saturation during sleep, or hypersomnolence during the day (table e12) [154, 157, 158].

In summary, the published data do not support the hypothesis that nasal dilators are effective in reducing snoring, or in improving sleep disordered breathing or sleep architecture in OSA. Nasal dilators are not recommended for reducing snoring, or for improving sleep disordered breathing or sleep architecture in OSA (D).

\section{SURGICAL THERAPY}

\section{Pathophysiological impact of nasal obstruction in the development of OSA}

Breathing through the human nose appears to have an effect on both ventilation and upper airway muscle tone. In an experimental study, McNicHOLAs et al. [159] previously demonstrated increased ventilation during nasal ventilation compared with mouth breathing. WHITE et al. [160] investigated the effects of local nasal anaesthesia on ventilation during sleep in healthy males. The application of lidocaine resulted in a four-fold increase in the number of both central and obstructive apnoeas, suggesting a stimulating effect of nasal airflow on respiratory muscle activity and upper airway stability. The latter has been confirmed by BASNER et al. [161], who demonstrated that nasal ventilation was associated with higher upper airway dilator muscle activity than breathing through the mouth in healthy volunteers. More recently, KOUTSOURELAKIS et al. [162] investigated the relationship between breathing route and apnoeic events in patients with OSA and controls. Patients with OSA had more frequent oral breathing epochs during sleep than controls. Oral breathing epochs furthermore correlated with respiratory disturbances during sleep.

It may be argued that nasal obstruction may predispose to sleep disordered breathing. In fact, a number of studies demonstrated an increased number of arousals, more frequent sleep stage changes, and/or an increase in the number of obstructive apnoeas and hypopnoeas during sleep associated with nasal occlusion under experimental nasal obstruction [163-165]. Similarly, there is evidence of sleep-related breathing disorders associated with nasal obstruction as a result of bilateral nasal packing after nasal surgery [166-169]. One potential limitation in these reports may be the potential influence of general anaesthesia on the prevalence of postoperative upper airway obstruction. In a recent report, however, ARMENGOT et al. [170] demonstrated equivalent episodes of nocturnal hypoxaemia, both in patients who had nasal packing postoperative nasal surgery and in those who had nasal packs for epistaxis but did not receive surgery.

In summary, there is evidence of a protective effect of nasal breathing on upper airway stability. The current literature furthermore suggests that patients with OSA are more likely to breathe through the high resistance pathway of the mouth, thereby promoting more negative intraluminal pressure in the pharynx, and predisposing to pharyngeal occlusion and, thus, OSA events. Moreover, there is evidence on both inducing and worsening of sleep disordered breathing due to nasal occlusion.

\section{Effects of nasal surgery on OSA}

Rationale

Due to the impact of nasal obstruction, improved nasal patency is expected to alleviate sleep disordered breathing. Furthermore, there is an expected relationship between nasal airway obstruction and CPAP tolerance, providing a physiological basis for improved CPAP compliance after nasal surgery [171]. Accordingly, the aim of this review is to assess the efficacy of nasal surgery on sleep apnoea severity, sleep quality and symptoms in adults with diagnosed OSA.

\section{Search criteria}

The authors performed searches in Pubmed and Medline. In addition, the authors underwent a manual search of the reference section of each cited article. Keyword combinations: OSA and nasal obstruction, OSA and nasal surgery, sleep apnoea and nasal surgery, sleep apnoea and nasal obstruction, sleep apnoea and nose, nasal ventilation and OSA. Studies with snorers only or those with sleep breathing disorders other than OSA, and studies in which nasal surgery was associated with other surgical procedures in the treated subject (i.e. adenotonsillectomy or others) were excluded.

\section{Overview of the evidence}

14 reports with adult patients suffering from mild to severe sleep disordered breathing and nasal obstruction have been published either as case series or retrospective analyses, and one report [172] was conducted as a prospective, randomised, sham-controlled trial (table e13) [172-183]. The most frequently observed pathologic finding in the preoperative ear, nose and throat examination was nasal obstruction due to deviated nasal septum. Accordingly, septal surgery (submucosal resection with or without turbinectomy) was the most frequently applied surgical technique in these reports. All the studies $(n=5)$ that have performed rhinomanometry reported significant postoperative improvements in total nasal resistance, indicating postoperative improvements in nasal airway patency in the patients. 
Only two studies [180, 181] reported significant improvements with regard to respiratory disturbances. One study [177] reported a significant improvement in AHI and sleep architecture in those with normal preoperative cephalometric measurements, but no beneficial effect in a group of patients with abnormal cephalometric measurements. There have been improvements in either sleepiness scales or daytime energy levels in six reports, and a reduction in therapeutic CPAP pressure required to alleviate OSA in two studies.

\section{Conclusions and recommendations}

Nasal surgery as a single intervention is not recommended for treatment of OSAS (C). Nasal surgery is recommended for reducing high therapeutic CPAP pressure due to nasal obstruction $(\mathrm{C})$.

\section{Tonsillectomy and tonsillotomy}

Rationale

The main upper airway anatomical alterations correlating with OSA include an enlarged tongue, soft thick palate, web posteriorised in relation to the oropharynx, long and thick uvula, and/or hypertrophic tonsils. Of note, those studies attempting to correlate the presence of anatomical alterations with disease severity found the highest correlations for tonsillar hypertrophy [184, 185]. While substantial bilateral tonsillar hypertrophy in adults is rather rare, adenotonsillar hypertrophy is the most common aetiology of OSA in children. The aim of this literature search was to assess the efficacy of surgical tonsillectomy on sleep apnoea severity, sleep quality, and symptoms in adults with OSA and tonsillar hypertrophy.

\section{Search criteria}

Databases individually searched: PubMed and Medline. Keyword combinations: tonsillectomy and obstructive sleep apnoea, tonsillotomy and obstructive sleep apnoea, tonsils and sleep, tonsillar hypertrophy and sleep apnoea, adenotonsillectomy and sleep apnoea. Studies with tonsillectomy by means of radiofrequency ablation, studies with tonsillectomy as part of UPPP or MLS, and reports on surgical outcomes of the upper airways without explicit information on sleep results in relation to tonsillectomy were excluded.

\section{Overview of the evidence in adults}

All reports have been published either as case series or retrospective analyses (table e14). Common to most of the reports is the lack of quality of life measures, the absence of a control group, and the lack of reporting surgical complication rates. More recent studies, however, reported consistent and significant improvements in the AHI after tonsillectomy. Despite significant improvements in respiratory parameters, there was evidence of residual sleep disordered breathing in most reports. More recent trials by MARTINHO et al. [186] and NAKATA et al. [187] investigated patients with OSA who where either intolerant to a CPAP trial or required high CPAP pressures to treat upper airway obstruction due to tonsillar hypertrophy. Based on these reports tonsillectomy play a role similar to nasal surgery in increasing the use of CPAP in patients with tonsillar hypertrophy, or when CPAP therapy is not possible as the first choice of therapy.

\section{Overview of the evidence in children}

38 "particular case-control studies" ( $\mathrm{n}=10$; evidence level $3 \mathrm{~b}$ ), case-control studies of limited quality $(n=2$; level 4$)$, and case series without controls $(n=26$; level 4$)$ investigating patients between 1 and 20 yrs of age who underwent (adeno)tonsillectomy were included in the analysis (table e15). Common to most reports is that the indication for surgery was based on evidence of upper airway obstruction, either by means of clinical signs or symptoms and/or poly(somno)graphically diagnosed sleep disordered breathing. Most studies investigated the effects of tonsillectomy as a combined procedure with adenoidectomy. The study population was very heterogeneous, including children who underwent tonsillectomy because of snoring, suspected OSA, poly(somno)graphically verified sleep apnoea (using an apnoea index (AI) $>1$ or AHI $>5 \mathrm{~h}^{-1}$ as a diagnostic cut-off), recurrent tonsillitis, and/or symptoms of upper airway obstruction without further explanation. Follow-up studies were performed between a few days postoperatively and up to 12 months after surgery.

All studies showed significant postoperative improvements in respiratory parameters.

Furthermore, there is some evidence of improved sleep architecture and improved quality of life scores, OSA symptom scores, and/or child behavioural scores. The literature also provides evidence for beneficial treatment effects beyond the reported outcomes on sleep parameters and quality of life scores, such as rapid increase in growth rate [188], improvement in insulin like growth factor-I levels [189], and improvements in systemic inflammation, lipid profiles and endothelial function [190]. Notably, most of the studies that investigated children with moderate to severe OSA observed persistent sleep disordered breathing in a clinically relevant proportion of children. Complete resolution of OSA was reported to be as low as $25 \%$ [191]. This raises important issues regarding the efficacy of adenotonsillectomy as the only intervention for OSA in children. Accordingly, repeated sleep testing has been recommended, particularly in those with persisting symptoms of upper airway obstruction (such as snoring) and/or in those with severely abnormal preoperative polysomnography results [192]

\section{Conclusions and recommendations}

Tonsillectomy as a single intervention is recommended for treatment of adult OSA in the presence of tonsillar hypertrophy (C). Adenotonsillectomy is recommended for treatment of childhood OSA in the presence of adenotonsillar hypertrophy (C).

\section{Radiofrequency surgery of the tonsils Rationale}

New techniques of tonsillectomy or tonsil volume reduction (tonsillotomy) are developed in order to reduce postoperative pain and bleeding rates. Temperature-controlled radiofrequency tonsil reduction is performed by introducing a probe into the tonsil and then heating to temperatures ranging from $40^{\circ} \mathrm{C}$ to $70^{\circ} \mathrm{C}$. A plasma field consisting of highly ionised particles is formed at the probe's surface that breaks down the molecular bonds of local tissue, with a reduction in heat dissipation to surrounding structures. The key innovation of radiofrequency tonsil reduction is the concept of subtotal 
intracapsular tonsil reduction that avoids injury to the pharyngeal constrictor muscles.

\section{Search criteria}

Databases individually searched: PubMed and Medline. Keywords: radiofrequency tonsillotomy and radiofrequency tonsil surgery for sleep apnoea. Articles dealing with paediatric samples, MLS, infectious tonsillar disease reviews, metaanalysis, case reports and guidelines were excluded.

\section{Overview of the evidence}

Four studies matching the inclusion criteria of this paper were found (table e16 and e17). No polysomnographic data were available in these studies.

NELSON [193] showed that performing radiofrequency ablation of the tonsils with the use of a two-needle probe does not damage the underlying pharyngeal muscle in vitro. A reduction of $70.8 \%$ in tonsil size was achieved in an in vivo study $(n=9)$ without postoperative bleeding. Moderate to severe postoperative pain on day one was present in four out of nine patients but disappeared over a 1-week period. An important improvement in subjective outcome, speech comfort, swallowing and throat irritation was reported. The same group confirmed these findings in a 12-month follow-up study in 12 patients with obstructive tonsil hypertrophy [194]. FRIEDMAN et al. [195] reported a reduction of 53.6\% in tonsil size after 12 weeks. The amount of tonsil reduction had a wide range and was unpredictable. Only mild postoperative pain was observed in all patients. No intra- or postoperative bleeding was noticed. However, radiofrequency tonsil reduction was not recommended as a standard technique for tonsil reduction. ERICSSON and HULTCRANTZ [196] compared efficacy and side-effects of tonsillotomy $(n=31)$ and tonsillectomy $(n=43)$ in patients with recurrent tonsillitis or obstructive hypertrophy. The tonsillotomy group had less intra-operative bleeding and no postoperative bleeding, while the tonsillectomy group had six postoperative bleedings. Postoperative pain was significantly less in the tonsillotomy group. In a follow-up study 1 yr after radiofrequency tonsillotomy, ERICSSON and HulTCRANTZ [196] showed that both tonsillotomy and tonsillectomy equally and effectively improved quality of life.

\section{Conclusions and recommendations}

Radiofrequency tonsil reduction appears to be a minimally invasive procedure with limited morbidity compared with tonsillectomy. The amount of tonsil reduction is significant but unpredictable. No conclusion on efficacy in OSA can be drawn since none of the studies included polysomnographic data. Radiofrequency tonsil reduction appears to have fewer sideeffects such as intra- and postoperative bleeding and less postoperative pain. Tonsil re-growth might occur but has not been studied thoroughly. Radiofrequency tonsil reduction is not recommended as a single procedure for the treatment of OSA (D).

\section{Uvulopalatopharyngoplasty and laser-assisted uvulopalatoplasty Rationale}

UPPP and laser-assisted uvulopalatoplasty (LAUP) aim to diminish anatomical upper airway obstruction at the oropharyngeal level by reducing soft palate redundancy [197]. UPPP enlarges the retropalatal airway by trimming and reorienting the posterior and anterior lateral pharyngeal pillars, and by excising the uvula and the posterior soft palate [197]. LAUP is an office-based surgical procedure that progressively shortens and tightens the uvula and palate through a series of carbon dioxide laser incisions and vaporisations [197]. In the large majority of apnoeic patients, upper airway collapses occur at multiple levels, i.e. both at the retropalatal level and behind the tongue base. Therefore, a surgical success with UPPP or LAUP can only be anticipated when pharyngeal collapse is limited to the retropalatal area, which is rarely the case in obese patients or those with severe sleep apnoea [198]. For these reasons, surgical procedures dedicated to the soft palate have been essentially studied in selected mild to moderate OSA populations with predominant oropharyngeal narrowing.

\section{Search criteria}

Databases individually searched: PubMed and Medline. Keyword combinations: sleep apnoea AND uvulopalatopharyngoplasty. Sleep apnoea AND LAUP or laser assisted uvulopalatoplasty. Limit: clinical trial; no other limitations. Only prospective studies were taken into account.

\section{Uvulopalatopharyngoplasty}

Overview of the evidence. Randomised clinical trials comparing UPPP to no treatment or sham surgery groups are lacking. Different definitions of clinical success are proposed, the most common that we will use in this review is a more than $50 \%$ reduction in AHI with a post-surgery $\mathrm{AHI}<20$ per h of sleep. The number of patients assessed is generally limited, with only few publications evaluating UPPP alone without adjunctive surgical procedure. Even prospective studies demonstrate nearly systematic inclusion biases. At the end, the majority of the available papers are clinical case series ranked as level 4 evidence. Interpretation of the "UPPP studies" is even more complex owing to the existence of many surgical techniques dedicated to the soft palate [199].

Overall, UPPP has a reported success rate of $\sim 50 \%$ in unselected populations of mild to moderate sleep apnoea $[197,198]$. In prospective studies (table e18) the mean success rate $(50 \%$ reduction in $\mathrm{AHI}$, an $\mathrm{AHI}$ of $\leqslant 20$, or both) ranged from 30 to $78 \%$. Such differences from one study to another are probably reflecting selection biases with potential good candidates being previously selected [200]. These studies also mainly included young or middle aged and lean subjects with mild to moderate sleep apnoea.

Failure of UPPP is usually attributed to secondary sites of obstruction located more caudally in the upper airway or to persistent retropalatal collapse due to an increased thickness of the soft palate after the procedure $[199,201]$. The percentage of patients attaining UPPP success was $52 \%$ in the case of isolated oropharyngeal obstruction compared with $5 \%$ in situations of associated retrolingual narrowing [202]. However, selecting appropriate patients for UPPP surgery remains challenging, as physical examination, imaging techniques, upper airway pressure measurements and endoscopic examination are not systematically used, and no evidence exists demonstrating that any criteria are sufficiently useful in predicting good surgical outcomes [200]. FRIEDMAN et al. [203] developed an anatomic staging system based on tongue-palate position, tonsil size and 
BMI to classify patients. In a case series, changes in AHI were significantly correlated with Friedman tongue position and tonsil size [200]. Patients with retrolingual collapse or narrowing, demonstrated by clinical criteria or by techniques evaluating upper airway size and/or function, should not be selected for UPPP surgery.

In the few studies having examined long-term evolution after surgery, efficacy of UPPP seems to diminish over time [88]. This seems to justify a long-term follow-up of these patients. UPPP is substantially less effective than the use of oral appliances [88, 204].

Other outcomes, such as subjective [205, 206] or objective sleepiness, sleep structure and fragmentation, quality of life [207] or cardiovascular changes, have been rarely reported. However, improvements of the Pittsburgh Sleep Quality Index, the Epworth Sleepiness Scale (ESS) [206], low grade inflammation [208], and endothelial function [209] have been described.

Serious life-threatening complications, including intubation difficulties, bleedings and acute upper airway obstruction, have been observed after UPPP with a $1.5 \%$ incidence and a mortaliy rate of $0.2 \%$ in a large prospective study including 3,130 patients [210]. Long-term side-effects (e.g. swallowing, globus sensation, voice changes or nasopharyngeal stenosis) persisted after UPPP in $58 \%$ of the patients [211]. Finally, having undergone UPPP has been proposed as a risk factor for CPAP non-compliance [212]. Leaks and mouth dryness are increased when using CPAP in patients with prior UPPP and may impair CPAP tolerance.

Conclusions and recommendations. UPPP is a single-level surgical procedure working only in selected patients with obstruction limited to the oropharyngeal area. UPPP cannot be recommended except in carefully selected patients (C). When proposing UPPP, potential benefits should be weighed against the risk of frequent long-term side-effects, among which velopharyngeal insufficiency, dry throat and abnormal swallowing, are the most common. Analysed studies were prospective but with selection biases, and therefore do not provide high-level evidence $(\mathrm{C})$.

\section{Laser-assisted uvuloplasty}

Overview of the evidence. Two randomised controlled trials are available [213, 214]. FERGUSON et al. [213] compared LAUP to conservative treatment in 46 mild OSA patients with a mean follow-up of 7 months. There was a statistically significant but not clinically relevant $21 \%$ reduction in AHI after LAUP (from 19 to $15 \mathrm{~h}^{-1}$ ) No improvement was found for subjective sleepiness and quality of life. Surgery reduced snoring intensity and frequency. LARROSA et al. [214] failed to find a difference between LAUP and a Sham surgery in sleepiness, quality of life or respiratory disturbances. After LAUP surgery, the airway is further compromised by oedema in the early postoperative period with a potential risk of OSA exacerbation (table e19).

Conclusion and recommendation. In mild OSA, LAUP has not demonstrated any significant effect neither on OSA severity nor in symptoms or quality of life domains and is therefore not recommended (B).

\section{Radiofrequency surgery of the soft palate}

Rationale

The term "radiofrequency surgery" in the context of palatal interventions is usually focused on interstitial electrosurgical treatment with stiffening of the tissue. Furthermore, cutting devices based on radiofrequency energy have also been developed to excise palatal tissue (radiofrequency assisted uvulopalatoplasty, RAUP) [215-217]. Finally, various combinations have been proposed, for example the combination of interstitial radiofrequency surgery and RAUP [218]. Tissue excision is usually performed as a single step procedure, whereas the interstitial application routinely requires repeated treatment session.

\section{Search criteria}

Databases individually searched: PubMed and Medline. Keyword combinations: "radiofrequency", "palate" and "sleep apnoea". Only studies using radiofrequency surgery as an isolated approach were analysed. Studies with patients with primary snoring were only selected with regard to morbidity and complications. In addition, a recent review was evaluated regarding potential additional publications [219]. Studies were excluded if they either did not provide sufficient objective outcome measures [220-222] or the baseline AHI was $<5$ [223] or $10[220,224,225]$ and the primary intention was to treat snoring.

\section{Overview of the evidence}

The data concerning OSA is limited and can hardly be compared due to the differences in devices and surgical techniques.

Improvements in respiratory parameters have been described in groups of mild to moderate and more severely affected patients under interstitial radiofrequency at the soft palate [226, 227]. Moreover, RAUP has been shown to be superior to interstitial radiofrequency surgery, but was associated with higher postoperative morbidity [217]. However, there are inconsistent findings in daytime sleepiness or other sleep parameters. A more recent, placebo-controlled study has shown that a single step radiofrequency intervention at the soft palate is not effective for the treatment of OSA (table e20) [228].

No serious adverse events after interstitial radiofrequency have been reported, though overall complication rates ranged from $0 \%$ to $50 \%$ [229-233]. The most frequently reported complication was mucosal erosion/ulceration. A small number of studies reported moderate complications in terms of severe palatal damage (palatal fistula, uvula loss/sloughing) [229, 230, 234, 235]. Postoperative pain was minimal in nearly all published papers [236-239]. No significant impact on fundamental frequency and formant frequency of vowels was detected. Postoperative morbidity of radiofrequency tissue resection or combined approaches appears higher [217, 218]. Nevertheless, postoperative pain after RAUP is still significantly less pronounced and postoperative morbidity is still significantly lower compared to LAUP [216].

\section{Conclusions and recommendations}

No controlled trials are available in sleep apnoea. All case series demonstrate a significant reduction in AHI after radiofrequency surgery. Radiofrequency surgery cannot be recommended, except in carefully selected patients (C). 


\section{Uvulopalatal flap}

Background

The uvulopalatal flap has been introduced as a modification of the classic UPPP [240]. By the removal of the oral mucosa and salivatory glands, and incisions bilaterally into the posterior pillar an uvulopalatal flap is created. This flap is rotated upwards and sutured into the defect. The main disadvantage compared to UPPP is that despite preservation of all muscles no visible uvula is left acting as lubricating structure for the palate.

\section{Search criteria}

Databases individually searched: PubMed and Medline. Keyword combinations: "uvulopalato or uvulopalatal and apnoea" and Boolean logic. 26 articles were further analysed. 13 articles were excluded (on the basis of language, reviews, expert opinions and not related with sleep disordered breathing).

\section{Overview of the evidence}

The evidence levels of the studies identified vary between $3 \mathrm{~b}$ and 4 . The data's evidence is restricted by the fact that the 12 studies are published by only three working groups. Therefore, it seems possible that several subjects might be included in multiple publications.

The procedure can be performed under local and general anaesthesia [241-243]. Complaints and complications are similar to a gentle UPPP [240]. Transient nasal regurgitation has been reported in $4 \%$ of the cases [241]. Permanent velopharyngeal incompetence or nasopharyngeal stenoses have not been reported so far. All working groups (six out of 12 studies) combined the uvulopalatal flap with other surgeries of the nose and/or the tongue base [240]. POWELL et al. [240] compared classic UPPP with the uvulopalatal flap in a group of 80 patients undergoing MLS (level of evidence $3 b$ ). The tongue base procedures were identical in both study groups. Both UPPP and the flap showed comparable results with regard to effectiveness for OSA, amount of tissue removed and complications. Six papers investigated the effect of an isolated uvulopalatal flap without any other surgeries at the same time [241, 244-248]. The AHI decreased significantly from 45 to 14 within 6-12 months after surgery. Surgical success (defined as 50\% reduction in AHI and reduction of AHI below 20) was calculated as $81.5 \%$. Significant improvement of quality of life as measured with the Mental Health 5 questionnaire [245]. Short Form 36 (SF-36), ESS and Snore Outcome Survey (SOS) were reported compared to baseline. All series were done by the same working group (table e21 and e22).

\section{Conclusions and recommendations}

Studies investigating the uvulopalatal flap with tonsillectomy for OSA show a significant improvement of the severity of OSA and quality of life. No controlled studies exist comparing the uvulopalatal flap to other treatment modalities for OSA. The levels of evidence of all studies were classified as 4 (C). So far, no cut-off points concerning BMI and AHI were identified limiting the use of the uvulopalatal flap. Therefore, it has to be kept in mind that surgical success rates decrease with increasing BMI and AHI in general. Various study groups found that the uvulopalatal flap may be combined with other surgeries of the nose and the tongue base in the sense of MLS with acceptable perioperative risk (3b). The uvulopalatal flap turned out to be as effective as UPPP (3b).

Due to a lack of evidence, uvulopalatal flaps are not recommended to treat simple snoring. Uvulopalatal flaps can be recommended for OSA in patients with palatal obstruction (C). Uvuloplatal flaps are a safe procedure that can be combined with other types of surgery within the upper airway to address OSA (B).

\section{Pillar method}

Rationale

The Pillar method consists of placing three cylindrical, nonresorbable polyethylenterephthalate implants (18 $\mathrm{mm}$ long) into and parallel to the midline of the soft palate with a distance of $3 \mathrm{~mm}$ to each other. The implants themselves, as well as the surrounding fibrosis, are intended to reduce threedimensional flutter of the soft palate and therefore inspiratory airway resistance [249].

\section{Search criteria}

Databases individually searched: PubMed and Medline. Keyword combinations: "palate", "implant" and "sleep apnoea". Only prospective studies were included. For the analysis of clinical outcome, only studies using the Pillar® technique as an isolated approach were analysed. Studies concerning snorers were only selected with regard to morbidity and complications. There is no experience in children so far.

\section{Overview of the evidence}

There are six case series and two randomised, placebocontrolled, double-blind trials (table e23). Placebo treatment consisted of inserting an empty delivery tool (no implant preloaded). Most studies included only patients with an AHI between 10 and $30, \mathrm{BMI}<32 \mathrm{~kg} \cdot \mathrm{m}^{-2}$, no or small palatine tonsils, and no sign of retrolingual collapse. Only FRIEDMAN et al. [252] included more obese patients (BMI $<40 \mathrm{~kg} \cdot \mathrm{m}^{-2}$ ). The six case series showed a reduction of the AHI $>50 \%$ and postoperative AHI $<10$ in $15-50 \%$ of the cases $3-15$ months after the procedure [250-254]. Both randomised, placebocontrolled, double-blind studies show a superiority of implants over placebo. However, results are conflicting, as STEWARD et al. [255] found a non-significant increase of AHI, in contrast to FRIEDMAN et al. [250], who reported a pronounced reduction of AHI. The ESS showed significant improvement in all case series and in the level $1 \mathrm{~b}$ study conducted by FRIEDMAN et al. [250]. No difference was found compared to the placebo group in the study of STEWARD et al. [255]. Functional parameters as assessed by questionnaires such as the SF-36 [250] and the Functional Outcomes of Sleep Questionnaire [255] demonstrated a significantly greater improvement in the treatment group compared to placebo.

Only minor discomfort, such as minor sore throat or foreign body sensation, was reported within the first 4 days postprocedure. Infections, mucosal irritations or ulcerations at the implant entrance site were reported in $<1 \%$ of the patients. Pain could be managed with simple analgesics such as paracetamol. There was no significant speech or swallowing disturbance after the procedure [256-260]. A partial extrusion happened in $10.3 \%$ of the patients or $4.1 \%$ of the implants in average. 


\section{Conclusions and recommendations}

Pillar ${ }^{\circledR}$ implants as an isolated procedure are superior to placebo and the respiratory results remain stable over the first 15 postoperative months but the overall success rate is limited. Therefore Pillar implants cannot be recommended and may only be considered in patients with mild to moderate OSA, who are suitable with regard to their overall physical condition (not or only moderately obese, no or small tonsils, no sign of retrolingual obstruction), if conservative approaches are not accepted by the patient (B).

\section{Tongue base and hypopharynx}

Radiofrequency surgery of the tongue base Rationale

Interstitial radiofrequency surgery of the tongue base was first investigated in a porcine model using a temperature-controlled radiofrequency device. The procedure turned out to be safe and was transferred to the use in patients suffering from OSA. Various different devices are available, although the majority of the published trials have used temperature-controlled radiofrequency surgery.

\section{Search criteria}

A literature search was performed in PubMed (US National Library of Medicine, Bethesda, MD, USA). Keyword combinations: "radiofrequency", "tongue" and "sleep apnoea". In addition, a recent review was evaluated regarding potential additional publications. For the analysis of clinical outcome, only studies using interstitial, transoral radiofrequency surgery as an isolated approach were analysed. Studies using combined approaches in terms of MLS were only selected with regard to morbidity and complications. Data regarding a transcervical radiofrequency approach were excluded. One study was excluded due to the high number of dropouts and the inhomogeneous mixed patient sample (snoring and OSA).

Overview of the evidence

In general, despite one comparative trial [261] only noncontrolled case series have been published. All studies have shown a statistically significant reduction in daytime sleepiness and all but two demonstrated a statistically significant reduction in AHI, although the overall effect seems limited (table e24) [262, 263]. Most trials presented follow-up periods of between 1 and 4 months. The longer term follow-up study (28 months) showed an increase in AHI indicating a relapse of OSA [264]. In contrast, STEWARD et al. [265] have documented the stability of the results at least over a median follow-up of 23 months. A series of noncontrolled trials has been published regarding combined radiofrequency surgery at the tongue base and the soft palate [266, 267]. However, WoODSON et al. [261] compared multilevel radiofrequency surgery at the tongue base and the soft palate with CPAP and placebo (sham CPAP). Although the AHI did not improve in the radiofrequency group, subjective and functional outcome measures improved significantly. Postoperative pain appears to be comparable to UPPP with tonsillectomy [263]. The postoperative complication rate varies between 0 and $41 \%$, and is mostly below $5 \%$ $[229,232,233,263,267-270]$. A severe potential complication is the formation of an abscess of the tongue base [229, 232, 262, 271]. No changes of swallowing or speech were observed [232, $263,267,271]$. The addition of radiofrequency surgery to other surgical approaches, such as UPPP, nasal surgery, tonsillar surgery, palatal implants or hyoid suspension, did not lead to an increase in morbidity [270, 272-277].

\section{Conclusions and recommendations}

The majority of the studies demonstrated a statistically significant, but limited, reduction in AHI and daytime sleepiness, although the data were based on noncontrolled case series with short follow-up periods (level of evidence $3 b$ ). Therefore, radiofrequency surgery of the tongue cannot generally be recommended as an isolated or combined procedure and may only be considered in selected patients with mild to moderate sleep apnoea intolerant to conservative treatment, as long as the overall condition appears suitable (non- or only moderately, obese patients with retrolingual obstruction) (C).

\section{Hyoid suspension}

Rationale

Hyoid suspension aims to avoid the back positioning of the tongue during sleep. Meanwhile, most surgeons favour the suspension of the hyoid to the thyroid cartilage with and without myotomies of the supra- and infrahyoid muscles.

\section{Search criteria}

Databases individually searched: PubMed and Medline. Keyword combinations: "hyoid suspension and apnoea" and Boolean logic. Variations of the catchwords were admitted. The remaining 21 articles were included in the analysis (table e25).

\section{Overview of the evidence}

The evidence levels of the studies identified vary between $3 \mathrm{~b}$ and 4. The perioperative risk of surgery is generally increased in OSA. In addition, temporary dysphagia up to 4 weeks, selflimited aspiration within the postoperative period, haematomas, seromas and disturbance of wound healing, as well as temporary articulation distortions, have been reported. Most authors use the hyoid suspension as a component of MLS for severe OSA secondarily after CPAP failure (table e25). Only three short-term studies investigated the effect of an isolated hyoid suspension for OSA [278-280]. The AHI decreased significantly from 36 to 21 after the hyoid suspension (table e26). The ESS score fell significantly from 8 at baseline to 5 after surgery [278, 280]. Two studies [281, 282] compared MLS with and without hyoid suspension. The concept including hyoid suspension was significantly more effective than the control group.

\section{Conclusions and recommendations}

The published data have to be regarded as preliminary. Randomised studies comparing the hyoid suspension with CPAP do not exist. The hyoid suspension is an invasive surgical technique, although the complication rate is moderate. Therefore, hyoid suspension may be combined with other procedures in MLS. The method may be considered in CPAP failure. Surgical success rates decrease with increasing BMI and $\mathrm{AHI}(\mathrm{C})$.

Due to a lack of evidence, hyoid suspension is not recommended for simple snoring. Hyoid suspension as an isolated procedure can be recommended for OSA in patients with retrolingual/hypopharnygeal obstruction (C). Hyoid suspension is a safe procedure that can be combined with other types of surgery within the upper airway (B). Hyoid suspension as a 
part of a MLS concept can be recommended for OSA in patients with combined retropalatal and retrolingual/hypopharnygeal obstruction (B).

\section{Tongue base and hypopharynx: partial tongue base resection and other treatments}

\section{Search criteria}

Keyword combination: tongue base surgery for sleep apnoea and hypopharyngeal surgery for sleep apnoea. Inclusion: studies where tongue base resection or tongue suspension were part of a multilevel approach are included. Medline search: tongue base surgery for sleep apnoea and hypopharyngeal surgery for sleep apnoea up to January 1, 2009. Reference lists of all identified articles were searched for additional studies.

\section{Overview of the evidence}

Laser midline glossectomy. It has been hypothesised that removal of a midline portion of the tongue base and excess tissue such as redundant lingual tonsils would enlarge the hypopharyngeal airway [283]. The intervention carries an inherent risk for significant postoperative pharyngolaryngeal oedema and requires a temporary tracheotomy. FuJITA et al. [283] and MicKelson and Rosenthal [284] included patients with severe persistent OSAS after UPPP and selection was based upon clinical examination and fibre-optic laryngoscopy with Mueller manoeuvre. Side-effects were considered minor and no persistent voice changes or dysphagia were reported. ANDSBERG and JESSEN [285] found a 50\% reduction in apnoea index in $56 \%$ of the subjects after 8 -yr follow-up. Of note, $23 \%$ complained of postoperative complications 98 months postoperatively (table e27).

Other approaches for tongue base reduction (plasty - resection) are summarised below and in table e28.

Tongue base reduction with hyoepiglottoplasty. CHABOLLE et al. [286] and SORRENTI et al. [287] performed a subtotal tongue base reduction through a cervical approach preceeded by lingual neurovascular bundle identification and derouting, epiglottal verticalisation, mouth floor horizontalisation, and hyoid bone repositioning, termed tongue base reduction with hyoepiglottoplasty, mostly combined with UPPP. A 100\% success rate was achieved at 6-month follow-up in severe OSA patients with severe macroglossia and hyolingual abnormalities in the absence of craniofacial deficiencies. Three out of 10 patients had swallowing abnormalities 6-19 months postoperatively, but all were able to resume a normal diet. The most relevant complication was a submental abscess which was attributed to the use of non-absorbable sutures.

Lingualplasty. WOODSON and FuJITA [288] modified the technique of laser midline glossectomy (LMG) to include lingualplasty in which tongue excision is extended more posterior and lateral. Candidates for lingualplasty were those with CPAP intolerance and upper airway collapse caused by large lingual tonsils or tongue base, rather than lateral wall collapse. Lingualplasty requires preoperative tracheotomy and, as described in the original paper, removal of additional lingual tonsils or redundant tissue of the epiglottis or arytenoids was included. In their series of 22 patients, eight had combined lingualplasty and UPPP, the remaining had lingualplasty alone. There was a significant perioperative complication rate $(27 \%)$, but no long-term complications, and the authors concluded that lingualplasty was more effective than LMG alone.

Lingual tonsillectomy. During LMG, the central part of the tongue is resected. Theoretically, this technique might have limited efficacy in selected patients with swollen lingual tonsils. LI et al. [289] compared the efficacy of combined treatment by extended uvulopalatal flap (EUPF) with either midline glossectomy or lingual tonsillectomy (LT) in a series of 12 consecutive non-obese OSA patients. They found that EUPF+LMG was highly effective in treating OSA in selected patients with type 2 obstruction (83\% success), whereas EUPF+LT was found to have no effect on OSA.

Palatopharyngoglossoplasty. DJUPESLAND et al. [290] developed a modified surgical technique based upon a combination of UPPP and removal of redundant tissue at the lateral aspects of the tongue base. AHI decreased from $54 \mathrm{~h}^{-1}$ (range 10-98 $\mathrm{h}^{-1}$ ) to $31 \mathrm{~h}^{-1}$ (range $0-61 \mathrm{~h}^{-1}$ ) in 20 OSA patients 8.7 months after palatopharyngoglossoplasty [291]. The AHI improved $>50 \%$ in $50 \%$ of the patients $(n=10)$.

Uvulopalatopharyngoglossoplasty. This technique combines UPPP with a bilateral resection of redundant soft tissue at the lateral aspects of the tongue base [292]. Screening oximetry and ambulatory polysomnography were repeated. The response rate in 19 OSA patients 6-12 months after surgery was $67 \%$ and no major complications were encountered.

Glossopexia. The glossopexia consists of a combination of a tongue resection plasty and an anterior suspension of the tongue using strips of fascia lata [293]. All of eight patients with persistent OSA after UPPP were tracheotomised and had subjective improvement, but reliable improvement documented by polysomnography after 12-24 months was obtained in only two patients. In addition, postoperative cephalometry did not reveal a change in the vertical or horizontal position of the hyoid bone or in the dimensions of the posterior airway space, but relevant side-effects, such as decreased sensitivity of the chin and tongue, immobility of the tongue, decreased sense of taste and slight difficulties of articulation, persistent oedema of the tongue, rejection of the fascia lata and serious infection of the tracheotomy spreading to the mediastium were reported. Therefore, this technique has no role in the surgical management of OSA.

The role of these modified techniques of glossopexia, palatopharyngoglossoplasty and uvulopalatopharyngoglossoplasty, and LT in the surgical treatment of OSA is unclear as no later reports on these techniques have been published so far.

Tongue base suspension. The Repose ${ }^{\circledR}$ system (InfluENT Inc $®$ ) is a minimally invasive surgical kit that uses a titanium screw and permanent suture to anchor/stabilise the tongue base to the inner mandibular cortex. Tightening of the suture provides support to the anterior hypopharyngeal airway and tongue base, thus preventing collapse at the retrolingual level. According to DeRowe et al. [294], the aim is not to permanently move the tongue forward, but rather to stabilise the tongue base level by adding rigidity of the scar tissue encased suture anchored anteriorly. The treatment is reversible as the 
suture can be removed. Patient selection was based upon fibreoptic examination and Mueller manoeuvre. The incidence of postoperative complications ranged from 15 to $33 \%$, and included infections with floor of mouth sialadenitis, dysphagia, odynophagia, development of floor of mouth cyst or haematoma. THOMAs et al. [295] performed a randomised controlled trial comparing tongue advancement (mandibular osteotomy) with tongue suspension (Repose $\left.{ }^{\circledR}\right)$. All patients underwent a simultaneous UPPP. There was no significant difference between both procedures in terms of response, postoperative pain, speech impairment or swallowing difficulties (table e29).

As the aim of the tongue suspension is to stabilise and support the tongue base, rather than to advance it, it not surprising that MiLLER et al. [296] and TERRIS et al. [297] failed to find relevant changes in the posterior airway space. A significant improvement in airway collapse at the palatal and tongue base level was demonstrated when Repose ${ }$ was combined with UPPP $[295,297]$

Patients with moderate to severe OSA have upper airway collapse at multiple levels of the upper airway involving the retropalatal and retroglossal region and varying contributions from the lateral pharyngeal walls. Therefore, some authors proposed a combined retropalatal/retroglossal approach by simultaneously performing a UPPP and a tongue suspension procedure $\left(\operatorname{Repose}_{\mathbb{R}}\right)$ [296, 298-300]. It is hard to delineate the relative contribution of each single procedure to the final outcome [299, 301]. SORRENTI et al. [298] suggested a limited role for tongue suspension in the surgical treatment of OSA as the results were inferior to those reported with genioglossus advancement and hyoid suspension in the treatment of retrolingual collapse. A second issue raised by these authors is the high cost of the $\operatorname{Repose}^{\circledR}$ kit and the probable poor stability of the suture over time [298].

\section{Summary}

Most studies on soft tissue tongue base surgery, excluding radiofrequency, were performed in subjects with severe OSA and concomitant obesity. In some reports, patients had already undergone upper airway surgery and were considered UPPP failures; others included patients who refused CPAP treatment. This selection bias is likely to affect the subjective appreciation of the results by the patients, which is mostly in contrast with the objective polysomnographic findings. The reviewed studies reported on significant improvements in snoring and daytime sleepiness. An improvement in the Functional Outcomes of Sleep Questionnaire score was reported in the study by WoODSON et al. [302] on tongue suspension.

Those studies that are limited to the use of one particular surgical technique have limitations in terms of number of patients included, design and time of follow-up. For those with a multilevel approach it is difficult to definitively define the efficacy of each procedure in terms of its contribution to a potential surgical cure.

\section{Conclusions and recommendations}

From the present data, it can be concluded that tongue base soft tissue procedures, such as partial resection of the tongue base and tongue suspension (Repose ${ }^{\circledR}$ ), cannot be recommended as a single treatment option for obese patients with moderate to severe OSA. The additional value of these techniques lies in the limited morbidity, the lack of cosmetic changes and the possibility to combine them with other procedures in a multilevel approach. There are at present no data to support their role in patients with mild disease (C).

\section{Genioglossus advancement \\ Rationale}

Genioglossus contraction enlarges both the velo- and the oropharynx and lowers the critical pressure without affecting the stiffness [116]. Nevertheless the genioglossus is only one of many muscles that act in concert to prevent flow limitation in the pharynx. Genioglossus advancement aims to enlarge the hypopharyngeal air space, bringing forward the base of tongue.

\section{Search criteria}

Databases individually searched: PubMed and Medline. Keyword combinations: genioglossus advancement, genioplasty and sleep, genioplasty and obstructive sleep apnoea, hypopharyngeal surgery and sleep, hypopharyngeal surgery and obstructive sleep apnoea, tongue surgery and obstructive sleep apnoea.

\section{Overview of the evidence}

Genioglossus advancement consists in an advancement of the genial tubercle and genioglossus muscle. A sliding genioplasty can be performed with a complete manipulation of the chin position that is moved forward with a portion of the inferior mandibular border and attached muscles. The second technique consists of a geniotomy with a rectangular bicortical osteotomy centered over the genial tubercle. Recently, a minimally invasive procedure has been developed (the $\operatorname{Repose}^{\circledR}$ system) which tries to reproduce the same effect with a tongue base suture suspension.

No study has investigated the effect of isolated genioglossus advancement for OSA. In MLS, when genioglossus advancement is the only hypopharyngeal procedure associated with velar surgery, genioglossus advancement demonstrated an improvement of postoperative AHI (table e30) with a success rate of $60 \%[303,304]$ in five series including 117 patients. The earliest studies realised between 1999 and 2004 in patients with severe OSAS demonstrated the best efficacy of genioglossus advancement on AHI.

\section{Conclusions and recommendations}

Genioglossus advancement seems to be efficiently used in MLS for treatment of hypopharyngeal airway impairment. Current research aims to optimise the identification of proper candidates for this surgery. Further studies are needed to identify an optimal strategy for targeted treatment of severe OSAS patients. Genioglossus advancement cannot be recommended as a single procedure for the surgical treatment of OSA (C).

\section{Maxillomandibular advancement \\ Rationale}

This surgery specifically addresses hypopharyngeal or tongue base obstruction in order to enlarge the retrolingual and retropalatal airway. An advancement of $10-15 \mathrm{~mm}$ of the maxilla and the mandible is necessary to be efficient when 
there is no maxillomandibular abnormality. In case of maxillomandibular abnormality the advancement must be more pronounced. The classical procedure consists in bilateral sagittal split ramus osteotomies with rigid internal fixation and Le Fort I osteotomy with rigid internal fixation [305-316]. The Stanford group [305] performs pharyngoplasty with or without hyoid myotomy suspension (phase I). MMA is performed in a second step (phase II) in case of failure of phase I. The rationale for using phase I is to avoid more radical and high-risk surgery when unnecessary, particularly in moderate OSA. Conversely, other groups proceed directly to MMA. Sometimes, mandibular elongation using osseous distraction followed by a Le Fort I advancement osteotomy is an efficient solution for difficult situations in order to obtain an easy advancement of $12-14 \mathrm{~mm}$ in 3 weeks [317]. This procedure needs close communication with the orthodontist. Successful surgery depends on proper patient selection, proper procedure selection and experience of the surgeon [197, 318].

\section{Search criteria}

Databases individually searched: PubMed and Medline. Keyword combinations: maxillomandibular advancement and sleep, maxillomandibular advancement and obstructive sleep apnoea, orthognathic surgery and sleep.

\section{Overview of the evidence}

The level of evidence is based on 12 series published between 1989 and 2006 (table e31) [305-316]. The baseline AHI varied between $>20$ and $>30$, success was defined by a post-surgical AHI between $<10$ and $<20$. The mean follow-up was performed between 6 weeks and 52 months. The success rate varied between $67 \%$ and $100 \%$ [305-307]. The discrepancy can be explained by different polysomnographic techniques [305-307]. A quarter of the remaining respiratory abnormalities were central events [306]. All series, including 298 patients, demonstrated an improvement of postoperative sleep macrostructure (table e31) [306-308]. Changes in excessive daytime sleepiness and MSLT after MMA were rarely documented.

PRINSELL [307] demonstrated a lowering of systolic and diastolic blood pressure after MMA, associated with weight loss. RILEY et al. [305] reported that $>50 \%$ of the patients treated by MMA no longer require antihypertensive medicines. However, there are no sufficient data on the efficacy of MMA on cardiovascular parameters.

In all series, patients usually undergo MMA surgery only after a complete clinical and cephalometric examination to evaluate the three major anatomic regions of potential upper airway obstruction: nose, palate (oropharynx) and base of tongue (hypopharynx) [305-316]. In some cases, pre-surgical evaluation is performed by a multidisciplinary team including a maxillofacial surgeon, a neurophysiologist and a pulmonologist [308, 314]. Selected patients are often male patients with an $\mathrm{AHI}>30$, aged $<60 \mathrm{yrs}$, with a BMI $<30 \mathrm{~kg} \cdot \mathrm{m}^{-2}$, and without relevant cardiovascular and pulmonary comorbidities (table e31).

All patients have to undergo overnight polysomnography according to widely accepted methods [319]. Alternatives to inlaboratory full polysomnography, especially in-home monitoring without EEG analysis, are not used due to insufficient detection of hypopnoeas or central events.
BETTEGA et al. [308] identified hypertrophic tonsils in 40\% and hypopharyngeal obstruction at the tongue base in $80 \%$ of the surgical candidates. This is generally explained by small oral cavities with a normal tongue size. All patients performed cephalometry before undergoing MMA in the 12 series (table e32). However, the results of the cephalometric analysis are not always reported [308]. OSA patients may present with pharyngeal narrowing at basal lingual level, sometimes in combination with retrognathia $\left(\mathrm{SNB}<77^{\circ}\right.$ ) or dolichofacial appearance [320]. Patients with a BMI $<30 \mathrm{~kg} \cdot \mathrm{m}^{-2}$ have shorter anterior floor of cranial base, a smaller mandible and retroposition of the mandible compared with severely obese patients [321]. These skeletal differences are associated with narrower velopharyngeal and linguopharyngeal spaces, predicting better surgical success. There is no sufficient evidence whether successful treatment by MADs is predictive for successful MMA surgery.

Several complications have been reported, including cardiac arrest without sequellae and dysrythmia [310], local infection, perforation of the palate, a maxillary pseudarthrosis, malocclusion, and dysgnathia due to mandibular deficiencies [305-309, 311-314]. All patients developed transient anaesthesia of the cheek and chin area. Residual neurosensitive deficit (hypoesthesia of the lower lip) was the most common complication, which did not affect quality of life in these patients. Patients who have a prior pharyngoplasty have temporary postoperative velar insufficiency (phonetic deficit and liquid regurgitation) improved by cautious speech therapy. Most of the patients accept changes in facial appearance, which can be predicted by preoperative computer imaging. The average postoperative offwork time is between 2 weeks [307] and 10 weeks [308, 309]. Full in-laboratory polysomnography should be performed between 2 and 6 months after surgery.

MMA has been shown to be effective over the long term [311, 322-324]. While WAITE et al. [310] confirmed long-term skeletal stability (12 months) based on cephalometric analysis, PEPIN [325] and others [92, 197, 311-329] demonstrated a deterioration of the results with a rate of success of $60 \%$ on a long-term basis. Ageing and weight gain appear to significantly impair long-term results.

\section{Conclusions and recommendations}

MMA seems to be as efficient as CPAP in patients with OSA who refuse conservative treatment [330], particularly in a young population without excessive BMI or other comorbidities. Therefore, MMA is recommended in this selected group of patients. However, essential benefit should be weighed against the risk of complications. The one-time cost of early MMA is probably far less expensive than multiple less successful surgeries or lifetime use of CPAP. Current research aims to optimise the identification of proper candidates for this surgery (B).

\section{Distraction osteogenesis}

Rationale

DOG is a surgical procedure applied in order to provide a lengthening of the bone associated with a stretching of the soft surrounding tissues [331]. Bone is osteotomised, and after a latency period, the device is activated progressively ( $\sim 1 \mathrm{~mm}$ per day) to induce bone healing and new bone 
formation. DOG can provide wide expansion and is thus very useful for the correction of severe maxillofacial anomalies in young children [332]. The procedure is used in different aetiologies of OSA especially in paediatric craniofacial malformations.

\section{Search criteria}

Databases individually searched: PubMed and Medline. Keywords combinations: distraction osteogenesis and sleep, distraction osteogenesis and obstructive sleep apnoea, surgery and sleep, surgery and obstructive sleep apnoea.

\section{Overview of the evidence}

Most of the articles are focused on mandibular DOG in paediatric micrognathia (table e33) (42 publications) [197, 317, 331-370]. They include several case reports and some retrospective and prospective series. The level of evidence remains low in such series $(2 b-4)$ with short series, lack of complete objective assessment, undefined criteria for patient selection and short-term follow-up. Only eight articles, from 1998 to 2009, were selected as they met the following criteria: mandibular lengthening in micrognathia, the confirmation of the diagnosis of sleep apnoea syndrome and objective evaluation of the benefit of the treatment. Other publications provide, however, interesting evidences of DOG benefit on children's respiratory status in order to avoid tracheostomy or to remove it.

DOG is used in craniofacial disorders associated with severe airway impairment as a result of micrognathia or midface hypoplasia. Retrusion of the inferior third of the face with micrognathia (Pierre Robin sequence, bilateral hemifacial microsomia (due to growth disturbance of the mandibula), Treacher Collins syndrome, Nager syndrome, temporomandibular joint (TMJ) ankylosis) might require mandibular advancement [336, 337, 347, 348, 355, 356, 364, 368]. Airway impairment is localised in the retroglossal area. Retrusion of the upper third of the facial skeleton (midface hypoplasia and retrusion) may need maxillo-zygomatic advancement (Le Fort III or monobloc advancement). In this case, airway impairment is localised on the velopharyngeal area. Syndromic faciocraniosynostosis (such as Crouzon, Apert or Pfeiffer syndrome) induces midfacial retrusion with velopharyngeal tissue obstruction [335]. The benefit on morphological improvement is associated with an enlargement of the posterior airway space. In significant numbers of these patients, tracheostomy is indicated when obstruction remains refractory to conservative management (particularly in neonates). But tracheostomy also provides significant morbidity and mortality $(0-3 \%)$ in young patients. Thus, in selected children, DOG is proposed to prevent tracheostomy or to achieve decannulation.

Indication of DOG remains controversial [354], particularly in non-syndromic micrognathia and Pierre Robin sequence. Nonsurgical handling in mild obstruction permits improvement in an important majority of cases [354], because of sufficient mandibular growth potential [351] and increase of tongue neuromuscular tone [364] within the first year of life. The review of the literature underlines the efficacy of DOG in OSA and breathing difficulties. However, there is no consensus on precise indications and timing of the procedure. Because of the potential complications of DOG in the neonate period, some authors avoid DOG in the first months [354, 356], and apply delayed distraction to decanulate tracheostomised children after 18-24 months [356]. In contrast, other authors use DOG in the first months of life in severe cases to avoid tracheostomy [341, 352, 363, 370]. GENECOV et al. [367] studied 81 patients with mandibular micrognathia (mostly Pierre Robin sequence) and airway obstruction syndrome over 11 yrs (mean age 1.2 yrs). Tracheostomy was prevented in $96 \%$, and decannulation achieved in $92 \%$. AHI decreased from 35-50 to 5-15 in 65 patients (two remained $>35$ ). The airway benefit of the DOG was evaluated by cephalometric analysis and three-dimensional computed tomography in several studies [341, 355, 368]. Cross-sectional space and skeletal lengthening increased significantly.

Faciocraniosynostosis (Crouzon, Apert or Pfeiffer syndrome) induce midfacial retrusion leading to variable sleep-related breathing disorders due to velopharyngeal obstruction in young patients and adults [339]. Midface advancement can relieve the obstruction and thus decrease sleep apnoea events and also lead to decannulation of tracheostomised patients. DOG can provide large magnitude advancement of the facial skeleton by progressive stretching of all the surrounding tissues compared to one-stage procedures. Two types of osteotomies can be performed: Le Fort III osteotomy (advancement of facial skeleton without cranial shape correction) or monobloc osteotomy (frontofacial advancement) within the first years of life. However, there are only few publications analysing the benefits on upper airway obstruction (table e34). There is less evidence on the efficacy of midface advancement on airway obstruction as compared to mandibular lengthening (C).

Numerous reports have demonstrated that DOG is also effective in adults [317], but it remains currently an optional treatment in selected patients (e.g. in TMJ ankylosis sequelae [347] and in facial cleft lip/palate sequellae). The procedure is limited by the risk of malocclusion due to incorrect distraction vectors parallelism, the length of the procedure, and discomfort of the device. Actually maxillomandibular advancement (MMA) can be provided in a single stage, without need of bone graft with a good stability and efficiency.

\section{Conclusions and recommendations}

Although there are only few publications to correctly evaluate its benefits, DOG is usefully applied and can be recommended in congenital micrognathia or midface hypoplasia. These indications may increase in the future, with less invasive procedures and adapted devices. Controversies, however, exist on early use to avoid tracheostomy in micrognathia. DOG may be indicated in selected adults or adolescents as MMA is surgically difficult to achieve. The efficiency of distraction advancement in OSAS treatment can be scored B in mandibular lengthening and $C$ in midface advancement.

\section{Multileve/ surgery}

\section{Rationale}

Most OSA patients have multilevel disease, including nasal obstruction, retropalatal and hypopharyngeal obstruction. The goal of MLS is to improve nasal airway blockage and both to enlarge the retropalatal airway and the retrolingual airway. At 
least surgery aims to correct anatomical abnormalities in the upper airway contributing to its collapse in the hypopharyngeal space during sleep. Nasal reconstructive surgeries include septal and/or bony intranasal reconstruction, alar valve or alar rim reconstruction and turbinectomy. UPPP, often combined with adenotonsillectomy, aims to trim and reorient the posterior and anterior lateral pharyngeal pillars by excising the uvula and the posterior portion of the palate. Mandibular osteotomy with genioglossus advancement, hyoid myotomy suspension, laser midline glossectomy with lingualplasty, and radiofrequency tongue base reduction (RTBR) aim to enlarge the retrolingual space.

\section{Search criteria}

Databases individually searched: PubMed and Medline. Keyword combinations: multilevel surgery and obstructive sleep apnoea, multilevel surgery and sleep, surgery and sleep.

\section{Overview of the evidence}

33 series including 1,431 patients published between 1992 and 2009 (table e34) [243, 273-275, 277, 281, 284-286, 288, 289, 291, 295, 299, 308, 313, 316, 371-387].

SUNDARAM et al. [388] recently reviewed the literature on surgery for OSA. No randomised trials could be identified. The authors emphasised methodological difficulties: variety of outcome measures, lack of long-term follow-up data and lack of consensus on the definition of "surgical success". The result of MLS efficiency was not reproducible in different studies. However, LIN et al. [389] focused on outcomes of OSA patients treated with MLS in a meta-analysis of 49 studies including 1,978 patients with a mean follow-up time of 7.3 months. The recalculated success rate was $66.4 \%$ with an overall complication rate of $14.6 \%$.

Studies evaluated here differed in terms of the preoperative AHI between $>5$ and $>30$, the definition of success (postsurgical AHI $<10$ to $<20$ ) and follow-up (6 weeks to 39 months) (table e35) [372, 373, 382, 384]. Success rate varied between $22.7 \%$ to $78 \%$ (mean $60.9 \%$ ) [299, 308]. Only RILEY et al. [375] and CHABOLLE et al. [286] reported a significant improvement in slow wave and REM sleep after MLS (table e36). The microarousal index or ESS scores were rarely reported by the authors [281]. There is no evidence of improvement in cardiovascular parameters after MLS.

As CPAP is the standard treatment for adult OSA, all attempts at improving effectiveness and adherence have to be undertaken prior to MLS. However, MLS may be considered in younger OSA patients in whom CPAP is unsuccessful or has been rejected for a long period.

In most of the series, patients usually undergo MLS surgery only after nasofibroscopy and a complete clinical and cephalometric examination to evaluate the three major anatomic regions of potential upper airway obstruction: nose, palate (oropharynx) and base of tongue (hypopharynx) [243, 273-275, 277, 281, 284-286, 288, 289, 291, 295, 299, 308, 313, 316, 371387]. The Friedman staging system is necessary to score the palate position and the tonsil size [275]. In some cases, presurgical evaluation is performed by a multidisciplinary team, including a maxillofacial surgeon, a neurophysiologist and a pulmonologist [308]. Severity of OSA disease was not a criterion for exclusion. Selected patients are often male, have an $\mathrm{AHI}>20$, are aged $<70 \mathrm{yrs}$ and have a BMI $<40 \mathrm{~kg} \cdot \mathrm{m}^{-2}$ (table e37). Patients with a history of respiratory or cardiac failure during the past year are excluded from performing MLS [299]. For BeTTEGA et al. [308], all OSA patients undergoing MLS have to be nonsmokers or have stopped smoking at least 1 month prior to surgery. At least patients with obvious micrognathia, bony anatomic abnormalities, without obvious palatal obstruction and patients who had previously failed surgical treatment with UPPP are thought to respond insufficiently to MLS.

All patients have to undergo overnight polysomnography prior to MLS surgery [319], which allows for detection of REM-related OSAS. MLS seems to be more effective in REM OSA patients. KAO et al. [385] reported a 100\% success rate in patients with $\mathrm{AHI}<30$ treated by MLS. It dropped to $50 \%$ in patients with AHI $>50$. LIU et al. [386] observed a higher success rate for OSA patients with an apnoea index $<25$. EuN et al. [373] observed a significant improvement of postoperative AHI after MLS (UPPP and RTBR) in 28 REM OSA patients $(8.1 \pm 6$ versus $14.5 \pm 7 ; \mathrm{p}<0.001)$, while there was no change in 62 non-REM OSA patients $(21 \pm 21$ versus $23.1 \pm 10$; $\mathrm{p}=0.374)$.

The success rate of MLS on AHI is about $53.6 \%$ at 6 months according to the analysis of the results of the 1,431 patients who underwent MLS. VICENTE et al. [299] studied the long-term efficacy of UPPP and hyoid myotomy suspension for severe OSA and reported a 78\% success rate at 3 yrs after MLS surgery. NERUNTARAT [243] observed the same results at 39 months for 49 OSA patients treated by UPPP and genioglossus advancement. ANDSBERG and JESSEN [285] observed the same results at 8 yrs.

BETTEGA et al. [308] identified hypertrophic tonsils in 40\% and hypopharyngeal obstruction at the base of tongue in $80 \%$ of the surgical candidates. This is generally explained by small oral cavities with a normal tongue size. Cephalometry was performed in most of the patients before undergoing MLS in the 32 series (table e38). Patients with a BMI $<30 \mathrm{~kg} \cdot \mathrm{m}^{-2}$ have shorter anterior floor of cranial base, a smaller mandible and retroposition of the mandible compared with severely obese patients [321]. These skeletal differences are associated with narrower velopharyngeal and linguopharyngeal spaces and predict better efficacy of MLS. Some authors performed the Muller manoeuvre during cephalometry to predict hypopharyngeal collapse [299, 389]. However, cephalometric radiographs did not differ between responders and nonresponders to MLS, hence, they are unable to predict surgical success.

A variety of side-effects can occur after MLS surgery, including velopharyngeal insufficiency, dysphagia, persistent dryness and nasopharyngeal stenosis (UPPP or uvuloflap), mandibular fracture, lesions of the roots of the teeth, infection, permanent anaesthesia of the lip and seroma (genioglossus advancement), odynophagia, postoperative oedema or excessive bleeding, often associated with incised epiglottis, requiring a protective tracheotomy (partial glossectomy), and tongue restriction (lingualplasty) [288]. Many patients have had subjective alterations in taste immediately postoperatively, which resolved spontaneously. Rare complications included angina pectoris 
[381], dysphagia and cricopharyngeus, haematoma of the mouth floor [376] and long-lasting hypoglossal nerve paresis [374].

\section{Conclusions and recommendations}

MLS cannot be recommended as a substitute for CPAP but as a salvage procedure for OSA patients in whom CPAP and other conservative therapies have failed. Surgical success of MLS for OSA is often unpredictable and less effective than CPAP. MLS seems to be more effective in mild to moderate REM-associated OSA, in patients aged $<60 \mathrm{yrs}$, and with $\mathrm{BMI}<30 \mathrm{~kg} \cdot \mathrm{m}^{-2}$, pharyngeal narrowing in the basal lingual area, retrognathia or dolichofacial appearance and without significant comorbidity. Success depends on appropriate patient selection, the type of surgical procedure performed and the experience of the surgeon. Most studies are retrospective and observational case series, and therefore do not provide high-level evidence (C). Further research should include larger, higher level studies that compare surgical procedures and identify factors associated with outcomes.

\section{STATEMENT OF INTEREST}

Statements of interest for S. Andreas, I. Smith, B.A. Stuck, J.T. Maurer and T. Verse can be found at www.erj.ersjournals.com $/ \mathrm{site} / \mathrm{misc} /$ statements.xhtml

\section{ACKNOWLEDGEMENTS}

The authors would like to thank C. Miltz (Bethanien Hospital, Institute of Pneumology, University Witten/Herdecke, Solingen, Germany) for her immense support in the preparation of the manuscript.

The authors' affiliation details are as follows. W.J. Randerath: Bethanien Hospital, Institute of Pneumology, University Witten/ Herdecke, Solingen, Germany; J. Verbraecken: Dept of Pulmonary Medicine, University Hospital Antwerp, Edegem, Belgium; S. Andreas: Lungenfachklinik Immenhausen, Immenhausen, Germany; G. Bettega: Service de Chirurgie Plastique et Maxillo-Faciale, CHU Grenoble, Grenoble Cedex, France; A. Boudewyns and E. Hamans: Dept of Otorhinolaryngology Head and Neck Surgery, University Hospital Antwerp, Edegem, Belgium; F. Jalbert: Dept of Maxillofacial Surgery, CHU Toulouse, Purpan, France; J.R. Paoli: Plastic and Maxillofacial Dept, CH Bastia, Bastia, France; B. Sanner: Bethesda Krankenhaus, Wuppertal, Germany; I. Smith: Respiratory Support and Sleep Centre, Papworth Hospital, University of Cambridge, Cambridge, UK; B.A. Stuck and J.T. Maurer: Sleep Disorders Center, Dept of Otorhinolaryngology, Head and Neck Surgery, University Hospital Mannheim, Mannheim, Germany; L. Lacassagne: Service de Pneumologie, Clinique de l'Union, Saint Jean, France; M. Marklund: Dept of Othodontics, Umea University, Umea, Sweden; J.L. Pepin: EFCR Sleep and Respiration Unit, CHU Grenoble, Grenoble Cedex, France; A. Valipour: Otto-Wagner-Hospital, Dept of Respiratory and Critical Care Medicine, Vienna, Austria; T. Verse: Dept of Otorhinolaryngology, Head and Neck Surgery, Asklepios Clinic Harburg, Harburg, Germany; and I. Fietze: Center of Interdisciplinary Sleep Medicine, Charité - Universitätsmedizin Berlin, CCM/CVK, Berlin, Germany.

\section{REFERENCES}

1 Sullivan CE, Issa FG, Berthon-Jones M, et al. Reversal of obstructive sleep apnoea by continuous positive airway pressure applied through the nares. Lancet 1981; 1: 862-865.

2 Chobanian AV, Bakris GL, Black HR, et al. Seventh report of the Joint National Committee on Prevention, Detection, Evaluation, and Treatment of High Blood Pressure. Hypertension 2003; 42: 1206-1252.
3 Marin JM, Carrizo SJ, Vicente E, et al. Long-term cardiovascular outcomes in men with obstructive sleep apnoea-hypopnoea with or without treatment with continuous positive airway pressure: an observational study. Lancet 2005; 365: 1046-1053.

4 Phillips B, Ball C. Levels of Evidence and Grades of Recommendation. Oxford, Oxford Centre for Evidence-Based Medicine, 2001.

5 Berger G, Berger R, Oksenberg A. Progression of snoring and obstructive sleep apnoea: the role of increasing weight and time. Eur Respir J 2009; 33: 338-345.

$6 \mathrm{He}$ J, Kryger MH, Zorick FJ, et al. Mortality and apnea index in obstructive sleep apnea. Experience in 385 male patients. Chest 1988; 94: 9-14.

7 Lavie P, Herer P, Lavie L. Mortality risk factors in sleep apnoea: a matched case-control study. J Sleep Res 2007; 16: 128-134.

8 Noda A, Okada T, Yasuma F, et al. Prognosis of the middle-aged and aged patients with obstructive sleep apnea syndrome. Psychiatry Clin Neurosci 1998; 52: 79-85.

9 Partinen M, Jamieson A, Guilleminault C. Long-term outcome for obstructive sleep apnea syndrome patients. Mortality. Chest 1988; 94: 1200-1204.

10 Young T, Finn L, Peppard PE, et al. Sleep disordered breathing and mortality: eighteen-year follow-up of the Wisconsin sleep cohort. Sleep 2008; 31: 1071-1078.

11 Punjabi NM, Caffo BS, Goodwin JL, et al. Sleep-disordered breathing and mortality: a prospective cohort study. PLoS Med 2009; 6: e1000132.

12 Tishler PV, Larkin EK, Schluchter MD, et al. Incidence of sleepdisordered breathing in an urban adult population: the relative importance of risk factors in the development of sleepdisordered breathing. JAMA 2003; 289: 2230-2237.

13 Young T, Peppard PE, Gottlieb DJ. Epidemiology of obstructive sleep apnea: a population health perspective. Am J Respir Crit Care Med 2002; 165: 1217-1239.

14 Redline S, Schluchter MD, Larkin EK, et al. Predictors of longitudinal change in sleep-disordered breathing in a nonclinic population. Sleep 2003; 26: 703-709.

15 Ancoli-Israel S, Gehrman P, Kripke DF, et al. Long-term followup of sleep disordered breathing in older adults. Sleep Med 2001; 2: 511-516.

16 Newman AB, Foster G, Givelber R, et al. Progression and regression of sleep-disordered breathing with changes in weight: the Sleep Heart Health Study. Arch Intern Med 2005; 165: 2408-2413.

17 Peppard PE, Young T, Palta M, et al. Longitudinal study of moderate weight change and sleep-disordered breathing. JAMA 2000; 284: 3015-3021.

18 Svanborg E, Larsson H. Development of nocturnal respiratory disturbance in untreated patients with obstructive sleep apnea syndrome. Chest 1993; 104: 340-343.

19 Lindberg E, Elmasry A, Gislason T, et al. Evolution of sleep apnea syndrome in sleepy snorers: a population-based prospective study. Am J Respir Crit Care Med 1999; 159: 2024-2027.

20 Pendlebury ST, Pepin JL, Veale D, et al. Natural evolution of moderate sleep apnoea syndrome: significant progression over a mean of 17 months. Thorax 1997; 52: 872-878.

21 Sahlman J, Pukkila M, Seppa J, et al. Evolution of mild obstructive sleep apnea after different treatments. Laryngoscope 2007; 117: 1107-1111.

22 Guilleminault C, Kirisoglu C, Poyares D, et al. Upper airway resistance syndrome: a long-term outcome study. J Psychiatr Res 2006; 40: 273-279.

23 Sforza E, Addati G, Cirignotta F, et al. Natural evolution of sleep apnoea syndrome: a five year longitudinal study. Eur Respir J 1994; 7: 1765-1770.

24 Fisher D, Pillar G, Malhotra A, et al. Long-term follow-up of untreated patients with sleep apnoea syndrome. Respir Med 2002; 96: 337-343. 
25 Shelton KE, Woodson H, Gay S, et al. Pharyngeal fat in obstructive sleep apnea. Am Rev Respir Dis 1993; 148: 462-466.

26 Oliven A, Aspandiarov E, Gankin I, et al. Collapsibility of the relaxed pharynx and risk of sleep apnoea. Eur Respir J 2008; 32: 1309-1315.

27 Schwartz AR, Gold AR, Schubert N, et al. Effect of weight loss on upper airway collapsibility in obstructive sleep apnea. Am Rev Respir Dis 1991; 144: 494-498.

28 Kalra $\mathrm{M}$, Inge $\mathrm{T}$, Garcia $\mathrm{V}$, et al. Obstructive sleep apnea in extremely overweight adolescents undergoing bariatric surgery. Obes Res 2005; 13: 1175-1179.

29 Rauscher H, Formanek D, Popp W, et al. Nasal CPAP and weight loss in hypertensive patients with obstructive sleep apnoea. Thorax 1993; 48: 529-533.

30 Charuzi I, Lavie P, Peiser J, et al. Bariatric surgery in morbidly obese sleep-apnea patients: short- and long-term follow-up. Am J Clin Nutr 1992; 55: Suppl. 2, 594S-596S.

31 Sugerman HJ, Fairman RP, Sood RK, et al. Long-term effects of gastric surgery for treating respiratory insufficiency of obesity. Am J Clin Nutr 1992; 55: Suppl. 2, 597S-601S.

32 Yee BJ, Phillips CL, Banerjee D, et al. The effect of sibutramineassisted weight loss in men with obstructive sleep apnoea. Int J Obes (Lond) 2007; 31: 161-168.

33 Ferland A, Poirier P, Series F. Sibutramine versus continuous positive airway pressure in obese obstructive sleep apnoea patients. Eur Respir J 2009; 34: 694-701.

34 Phillips CL, Yee BJ, Trenell MI, et al. Changes in regional adiposity and cardio-metabolic function following a weight loss program with sibutramine in obese men with obstructive sleep apnea. J Clin Sleep Med 2009; 5: 416-421.

35 Lettieri CJ, Eliasson AH, Greenburg DL. Persistence of obstructive sleep apnea after surgical weight loss. J Clin Sleep Med 2008; 4: 333-338.

36 Lojander J, Mustajoki P, Ronka S, et al. A nurse-managed weight reduction programme for obstructive sleep apnoea syndrome. $J$ Intern Med 1998; 244: 251-255.

37 Kajaste S, Brander PE, Telakivi T, et al. A cognitive-behavioral weight reduction program in the treatment of obstructive sleep apnea syndrome with or without initial nasal CPAP: a randomized study. Sleep Med 2004; 5: 125-131.

38 Rasheid S, Banasiak M, Gallagher SF, et al. Gastric bypass is an effective treatment for obstructive sleep apnea in patients with clinically significant obesity. Obes Surg 2003; 13: 58-61.

39 Busetto L, Enzi G, Inelmen EM, et al. Obstructive sleep apnea syndrome in morbid obesity: effects of intragastric balloon. Chest 2005; 128: 618-623.

40 Charuzi I, Fraser D, Peiser J, et al. Sleep apnea syndrome in the morbidly obese undergoing bariatric surgery. Gastroenterol Clin North Am 1987; 16: 517-519.

41 Valencia-Flores M, Orea A, Herrera M, et al. Effect of bariatric surgery on obstructive sleep apnea and hypopnea syndrome, electrocardiogram, and pulmonary arterial pressure. Obes Surg 2004; 14: 755-762.

42 Cartwright RD. Effect of sleep position on sleep apnea severity. Sleep 1984; 7: 110-114.

43 George CF, Millar TW, Kryger MH. Sleep apnea and body position during sleep. Sleep 1988; 11: 90-99.

44 McEvoy RD, Sharp DJ, Thornton AT. The effects of posture on obstructive sleep apnea. Am Rev Respir Dis 1986; 133: 662-666.

45 Petruson B. Improvement of the nasal airflow by the nasal dilator Nozovent. Rhinology 1988; 26: 289-292.

46 Phillips BA, Okeson J, Paesani D, et al. Effect of sleep position on sleep apnea and parafunctional activity. Chest 1986; 90: 424-429.

47 Issa FG, Sullivan CE. Upper airway closing pressures in obstructive sleep apnea. J Appl Physiol 1984; 57: 520-527.
48 Pevernagie DA, Stanson AW, Sheedy PF 2nd, et al. Effects of body position on the upper airway of patients with obstructive sleep apnea. Am J Respir Crit Care Med 1995; 152: 179-185.

49 Shepard JW Jr, Burger CD. Nasal and oral flow-volume loops in normal subjects and patients with obstructive sleep apnea. Am Rev Respir Dis 1990; 142: 1288-1293.

50 Chan AS, Lee RW, Cistulli PA. Non-positive airway pressure modalities: mandibular advancement devices/positional therapy. Proc Am Thorac Soc 2008; 5: 179-184.

51 Oksenberg A, Silverberg DS, Arons E, et al. Positional vs nonpositional obstructive sleep apnea patients: anthropomorphic, nocturnal polysomnographic, and multiple sleep latency test data. Chest 1997; 112: 629-639.

52 Maurer JT, Stuck BA, Hein G, et al. Schlafapnoetherapie mit einer neuartigen Rückenlage-Verhinderungs-Weste. [Treatment of obstructive sleep apnea with a new vest preventing the supine position.] Dtsch Med Wochenschr 2003; 128: 71-75.

53 Zuberi NA, Rekab K, Nguyen HV. Sleep apnea avoidance pillow effects on obstructive sleep apnea syndrome and snoring. Sleep Breath 2004; 8: 201-207.

54 Cartwright RD, Lloyd S, Lilie J, et al. Sleep position training as treatment for sleep apnea syndrome: a preliminary study. Sleep 1985; 8: 87-94.

55 Jokic R, Klimaszewski A, Crossley M, et al. Positional treatment vs continuous positive airway pressure in patients with positional obstructive sleep apnea syndrome. Chest 1999; 115: 771-781.

56 Wenzel S, Smith E, Leiacker R, et al. Effektivität und LangzeitCompliance der Therapie mit Rückenlage-Verhinderungsweste bei obstruktiver Schlafapnoe. [Efficacy and longterm compliance of the vest preventing the supine position in patients with obstructive sleep apnea.] Laryngorhinootologie 2007; 86 579-583.

57 Loord H, Hultcrantz E. Positioner-a method for preventing sleep apnea. Acta Otolaryngol 2007; 127: 861-868.

58 Oksenberg A, Silverberg D, Offenbach D, et al. Positional therapy for obstructive sleep apnea patients: a 6-month follow-up study. Laryngoscope 2006; 116: 1995-2000.

59 Cartwright R, Ristanovic R, Diaz F, et al. A comparative study of treatments for positional sleep apnea. Sleep 1991; 14: 546-552.

60 Berger M, Oksenberg A, Silverberg DS, et al. Avoiding the supine position during sleep lowers $24 \mathrm{~h}$ blood pressure in obstructive sleep apnea (OSA) patients. J Hum Hypertens 1997; 11: 657-664.

61 Skinner MA, Kingshott RN, Jones DR, et al. Elevated posture for the management of obstructive sleep apnea. Sleep Breath 2004; 8: 193-200.

62 Hans MG, Nelson S, Luks VG, et al. Comparison of two dental devices for treatment of obstructive sleep apnea syndrome (OSAS). Am J Orthod Dentofacial Orthop 1997; 111: 562-570.

63 Mehta A, Qian J, Petocz P, et al. A randomized, controlled study of a mandibular advancement splint for obstructive sleep apnea. Am J Respir Crit Care Med 2001; 163: 1457-1461.

64 Gotsopoulos H, Chen C, Qian J, et al. Oral appliance therapy improves symptoms in obstructive sleep apnea: a randomized, controlled trial. Am J Respir Crit Care Med 2002; 166: 743-748.

65 Johnston CD, Gleadhill IC, Cinnamond MJ, et al. Mandibular advancement appliances and obstructive sleep apnoea: a randomized clinical trial. Eur J Orthod 2002; 24: 251-262.

66 Barnes M, McEvoy RD, Banks S, et al. Efficacy of positive airway pressure and oral appliance in mild to moderate obstructive sleep apnea. Am J Respir Crit Care Med 2004; 170: 656-664.

67 Blanco J, Zamarron C, Abeleira Pazos MT, et al. Prospective evaluation of an oral appliance in the treatment of obstructive sleep apnea syndrome. Sleep Breath 2005; 9: 20-25.

68 Naismith SL, Winter VR, Hickie IB, et al. Effect of oral appliance therapy on neurobehavioral functioning in obstructive sleep apnea: a randomized controlled trial. J Clin Sleep Med 2005; 1: 374-380. 
69 Lam B, Sam K, Mok WY, et al. Randomised study of three nonsurgical treatments in mild to moderate obstructive sleep apnoea. Thorax 2007; 62: 354-359.

70 Petri N, Svanholt P, Solow B, et al. Mandibular advancement appliance for obstructive sleep apnoea: results of a randomised placebo controlled trial using parallel group design. J Sleep Res 2008; 17: 221-229.

71 Ferguson KA, Ono T, Lowe AA, et al. A randomized crossover study of an oral appliance vs nasal-continuous positive airway pressure in the treatment of mild-moderate obstructive sleep apnea. Chest 1996; 109: 1269-1275.

72 Ferguson KA, Ono T, Lowe AA, et al. A short-term controlled trial of an adjustable oral appliance for the treatment of mild to moderate obstructive sleep apnoea. Thorax 1997; 52: 362-368.

73 Engleman HM, McDonald JP, Graham D, et al. Randomized crossover trial of two treatments for sleep apnea/hypopnea syndrome: continuous positive airway pressure and mandibular repositioning splint. Am J Respir Crit Care Med 2002; 166: 855-859.

74 Randerath WJ, Heise M, Hinz R, et al. An individually adjustable oral appliance $v s$ continuous positive airway pressure in mild-tomoderate obstructive sleep apnea syndrome. Chest 2002; 122: 569-575.

75 Tan YK, L'Estrange PR, Luo YM, et al. Mandibular advancement splints and continuous positive airway pressure in patients with obstructive sleep apnoea: a randomized cross-over trial. Eur J Orthod 2002; 24: 239-249.

76 Hoekema A, Stegenga B, Wijkstra PJ, et al. Obstructive sleep apnea therapy. J Dent Res 2008; 87: 882-887.

77 Gagnadoux F, Fleury B, Vielle B, et al. Titrated mandibular advancement versus positive airway pressure for sleep apnoea. Eur Respir J 2009; 34: 914-920.

78 Bloch KE, Iseli A, Zhang JN, et al. A randomized, controlled crossover trial of two oral appliances for sleep apnea treatment. Am J Respir Crit Care Med 2000; 162: 246-251.

79 Pitsis AJ, Darendeliler MA, Gotsopoulos H, et al. Effect of vertical dimension on efficacy of oral appliance therapy in obstructive sleep apnea. Am J Respir Crit Care Med 2002; 166: 860-864.

80 Rose E, Staats R, Virchow C, et al. A comparative study of two mandibular advancement appliances for the treatment of obstructive sleep apnoea. Eur J Orthod 2002; 24: 191-198.

81 Tegelberg A, Walker-Engstrom ML, Vestling O, et al. Two different degrees of mandibular advancement with a dental appliance in treatment of patients with mild to moderate obstructive sleep apnea. Acta Odontol Scand 2003; 61: 356-362.

82 Walker-Engstrom ML, Ringqvist I, Vestling $\mathrm{O}$, et al. A prospective randomized study comparing two different degrees of mandibular advancement with a dental appliance in treatment of severe obstructive sleep apnea. Sleep Breath 2003; 7: 119-130.

83 Lawton HM, Battagel JM, Kotecha B. A comparison of the Twin Block and Herbst mandibular advancement splints in the treatment of patients with obstructive sleep apnoea: a prospective study. Eur J Orthod 2005; 27: 82-90.

84 Gauthier L, Laberge L, Beaudry M, et al. Efficacy of two mandibular advancement appliances in the management of snoring and mild-moderate sleep apnea: a cross-over randomized study. Sleep Med 2009; 10: 329-336.

85 Vanderveken OM, Devolder A, Marklund M, et al. Comparison of a custom-made and a thermoplastic oral appliance for the treatment of mild sleep apnea. Am J Respir Crit Care Med 2008; 178: 197-202.

86 Ghazal A, Sorichter S, Jonas I, et al. A randomized prospective long-term study of two oral appliances for sleep apnoea treatment. J Sleep Res 2009; 18: 321-328.

87 Aarab G, Lobbezoo F, Hamburger HL, et al. Effects of an oral appliance with different mandibular protrusion positions at a constant vertical dimension on obstructive sleep apnea. Clin Oral Investig 2010; 14: 339-345.

88 Walker-Engstrom ML, Tegelberg A, Wilhelmsson B, et al. 4-year follow-up of treatment with dental appliance or uvulopalatopharyngoplasty in patients with obstructive sleep apnea: a randomized study. Chest 2002; 121: 739-746.

89 Kyung SH, Park YC, Pae EK. Obstructive sleep apnea patients with the oral appliance experience pharyngeal size and shape changes in three dimensions. Angle Orthod 2005; 75: 15-22.

$90 \mathrm{Ng} \mathrm{AT}$, Gotsopoulos H, Qian J, et al. Effect of oral appliance therapy on upper airway collapsibility in obstructive sleep apnea. Am J Respir Crit Care Med 2003; 168: 238-241.

91 Fleury B, Rakotonanahary D, Petelle B, et al. Mandibular advancement titration for obstructive sleep apnea: optimization of the procedure by combining clinical and oximetric parameters. Chest 2004; 125: 1761-1767.

92 Marklund M, Stenlund H, Franklin KA. Mandibular advancement devices in 630 men and women with obstructive sleep apnea and snoring: tolerability and predictors of treatment success. Chest 2004; 125: 1270-1278.

93 Liu Y, Lowe AA, Fleetham JA, et al. Cephalometric and physiologic predictors of the efficacy of an adjustable oral appliance for treating obstructive sleep apnea. Am J Orthod Dentofacial Orthop 2001; 120: 639-647.

94 Gotsopoulos H, Kelly JJ, Cistulli PA. Oral appliance therapy reduces blood pressure in obstructive sleep apnea: a randomized, controlled trial. Sleep 2004; 27: 934-941.

95 Coruzzi P, Gualerzi M, Bernkopf E, et al. Autonomic cardiac modulation in obstructive sleep apnea: effect of an oral jawpositioning appliance. Chest 2006; 130: 1362-1368.

96 Itzhaki S, Dorchin H, Clark G, et al. The effects of 1-year treatment with a herbst mandibular advancement splint on obstructive sleep apnea, oxidative stress, and endothelial function. Chest 2007; 131: 740-749.

97 Trzepizur W, Gagnadoux F, Abraham P, et al. Microvascular endothelial function in obstructive sleep apnea: Impact of continuous positive airway pressure and mandibular advancement. Sleep Med 2009; 10: 746-752.

98 Hoekema A, Voors AA, Wijkstra PJ, et al. Effects of oral appliances and CPAP on the left ventricle and natriuretic peptides. Int J Cardiol 2008; 128: 232-239.

99 Hoekema A, Stegenga B, Bakker M, et al. Simulated driving in obstructive sleep apnoea-hypopnoea; effects of oral appliances and continuous positive airway pressure. Sleep Breath 2007; 11: 129-138.

100 Kato J, Isono S, Tanaka A, et al. Dose-dependent effects of mandibular advancement on pharyngeal mechanics and nocturnal oxygenation in patients with sleep-disordered breathing. Chest 2000; 117: 1065-1072.

101 Dort LC, Hadjuk E, Remmers JE. Mandibular advancement and obstructive sleep apnoea: a method for determining effective mandibular protrusion. Eur Respir J 2006; 27: 1003-1009.

102 Lowe AA, Sjoholm TT, Ryan CF, et al. Treatment, airway and compliance effects of a titratable oral appliance. Sleep 2000; 23: Suppl. 4, S172-S178.

103 Dort L, Brant R. A randomized, controlled, crossover study of a noncustomized tongue retaining device for sleep disordered breathing. Sleep Breath 2008; 12: 369-373.

104 Deane SA, Cistulli PA, Ng AT, et al. Comparison of mandibular advancement splint and tongue stabilizing device in obstructive sleep apnea: a randomized controlled trial. Sleep 2009; 32: 648-653.

105 Barthlen GM, Brown LK, Wiland MR, et al. Comparison of three oral appliances for treatment of severe obstructive sleep apnea syndrome. Sleep Med 2000; 1: 299-305.

106 Higurashi N, Kikuchi M, Miyazaki S, et al. Effectiveness of a tongue-retaining device. Psychiatry Clin Neurosci 2002; 56: 331-332. 
107 Kingshott RN, Jones DR, Taylor DR, et al. The efficacy of a novel tongue-stabilizing device on polysomnographic variables in sleepdisordered breathing: a pilot study. Sleep Breath 2002; 6: 69-76.

108 Remmers JE, deGroot WJ, Sauerland EK, et al. Pathogenesis of upper airway occlusion during sleep. J Appl Physiol 1978; 44: 931-938.

109 Deegan PC, McNicholas WT. Pathophysiology of obstructive sleep apnea. Eur Respir Mon 1998; 3: 28-62.

110 Mezzanotte WS, Tangel DJ, White DP. Waking genioglossal electromyogram in sleep apnea patients versus normal controls (a neuromuscular compensatory mechanism). J Clin Invest 1992; 89: 1571-1579.

111 Wiegand DA, Latz B, Zwillich CW, et al. Upper airway resistance and geniohyoid muscle activity in normal men during wakefulness and sleep. J Appl Physiol 1990; 69: 1252-1261.

112 Schwartz AR, Eisele DW, Hari A, et al. Electrical stimulation of the lingual musculature in obstructive sleep apnea. J Appl Physiol 1996; 81: 643-652.

113 Mann EA, Burnett T, Cornell S, et al. The effect of neuromuscular stimulation of the genioglossus on the hypopharyngeal airway. Laryngoscope 2002; 112: 351-356.

114 Oliven A, O'Hearn DJ, Boudewyns A, et al. Upper airway response to electrical stimulation of the genioglossus in obstructive sleep apnea. J Appl Physiol 2003; 95: 2023-2029.

115 Oliven A, Schnall RP, Pillar G, et al. Sublingual electrical stimulation of the tongue during wakefulness and sleep. Respir Physiol 2001; 127: 217-226.

116 Oliven A, Tov N, Geitini L, et al. Effect of genioglossus contraction on pharyngeal lumen and airflow in sleep apnoea patients. Eur Respir J 2007; 30: 748-758.

117 Isono S, Tanaka A, Nishino T. Effects of tongue electrical stimulation on pharyngeal mechanics in anaesthetized patients with obstructive sleep apnoea. Eur Respir J 1999; 14: 1258-1265.

118 Schnall RP, Pillar G, Kelsen SG, et al. Dilatory effects of upper airway muscle contraction induced by electrical stimulation in awake humans. J Appl Physiol 1995; 78: 1950-1956.

119 Miki H, Hida W, Chonan T, et al. Effects of submental electrical stimulation during sleep on upper airway patency in patients with obstructive sleep apnea. Am Rev Respir Dis 1989; 140: 1285-1289.

120 Guilleminault C, Powell N, Bowman B, et al. The effect of electrical stimulation on obstructive sleep apnea syndrome. Chest 1995; 107: 67-73.

121 Decker MJ, Haaga J, Arnold JL, et al. Functional electrical stimulation and respiration during sleep. J Appl Physiol 1993; 75: 1053-1061.

122 Wiltfang J, Klotz S, Jordan W, et al. Erste Ergebnisse zum Training der suprahyoidalen Muskulatur bei Probanden und einem Patienten mit obstruktiver Schlafapnoe. [First results of training of the suprahyoidal muscles via electrostimulation in healthy subjects and in a patient with sleep apnea.] Somnologie 1997; 1: 160-164.

123 Verse T, Schwalb J, Hormann K, et al. Transkutane, submentale Elektrostimulationstherapie bei obstruktiver Schlafapnoe. [Submental transcutaneous electrical stimulation for obstructive sleep apnea.] HNO 2003; 51: 966-970.

124 Randerath WJ, Galetke W, Domanski U, et al. Tongue-muscle training by intraoral electrical neurostimulation in patients with obstructive sleep apnea. Sleep 2004; 27: 254-259.

125 Puhan MA, Suarez A, Lo Cascio C, et al. Didgeridoo playing as alternative treatment for obstructive sleep apnoea syndrome: randomised controlled trial. BMJ 2006; 332: 266-270.

126 Guimaraes KC, Drager LF, Genta PR, et al. Effects of oropharyngeal exercises on patients with moderate obstructive sleep apnea syndrome. Am J Respir Crit Care Med 2009; 179: 962-966.

127 Smith I, Lasserson TJ, Wright J. Drug therapy for obstructive sleep apnoea in adults. Cochrane Database Syst Rev 2006; CD003002.
128 Brownell LG, West $\mathrm{P}$, Sweatman $\mathrm{P}$, et al. Protriptyline in obstructive sleep apnea: a double-blind trial. N Engl J Med 1982; 307: 1037-1042.

129 Stepanski EJ, Conway WA, Young DK, et al. A double-blind trial of protriptyline in the treatment of sleep apnea syndrome. Henry Ford Hosp Med J 1988; 36: 5-8.

130 Whyte KF, Gould GA, Airlie MA, et al. Role of protriptyline and acetazolamide in the sleep apnea/hypopnea syndrome. Sleep 1988; 11: 463-472.

131 Berry RB, Yamaura EM, Gill K, et al. Acute effects of paroxetine on genioglossus activity in obstructive sleep apnea. Sleep 1999; 22: 1087-1092.

132 Kraiczi H, Hedner J, Dahlof $\mathrm{P}$, et al. Effect of serotonin uptake inhibition on breathing during sleep and daytime symptoms in obstructive sleep apnea. Sleep 1999; 22: 61-67.

133 Carley DW, Olopade C, Ruigt GS, et al. Efficacy of mirtazapine in obstructive sleep apnea syndrome. Sleep 2007; 30: 35-41.

134 Marshall NS, Yee BJ, Desai AV, et al. Two randomized placebocontrolled trials to evaluate the efficacy and tolerability of mirtazapine for the treatment of obstructive sleep apnea. Sleep 2008; 31: 824-831.

135 Hedner J, Kraiczi H, Peker Y, et al. Reduction of sleep-disordered breathing after physostigmine. Am J Respir Crit Care Med 2003; 168: 1246-1251.

136 Jokic R, Klimaszewski A, Mink J, et al. Surface tension forces in sleep apnea: the role of a soft tissue lubricant: a randomized double-blind, placebo-controlled trial. Am J Respir Crit Care Med 1998; 157: 1522-1525.

137 Hellgren J, Omenaas E, Gislason T, et al. Perennial non-infectious rhinitis-an independent risk factor for sleep disturbances in asthma. Respir Med 2007; 101: 1015-1020.

138 Canova CR, Downs SH, Knoblauch A, et al. Increased prevalence of perennial allergic rhinitis in patients with obstructive sleep apnea. Respiration 2004; 71: 138-143.

139 Zhang L, Mendoza-Sassi RA, César JA, et al. Intranasal corticosteroids for nasal airway obstruction in children with moderate to severe adenoidal hypertrophy. Cochrane Database Syst Rev 2008; CD006286.

140 Kiely JL, Nolan P, McNicholas WT. Intranasal corticosteroid therapy for obstructive sleep apnoea in patients with co-existing rhinitis. Thorax 2004; 59: 50-55.

141 Brouillette RT, Manoukian JJ, Ducharme FM, et al. Efficacy of fluticasone nasal spray for pediatric obstructive sleep apnea. J Pediatr 2001; 138: 838-844.

142 Mansfield LE, Diaz G, Posey CR, et al. Sleep disordered breathing and daytime quality of life in children with allergic rhinitis during treatment with intranasal budesonide. Ann Allergy Asthma Immunol 2004; 92: 240-244.

143 Alexopoulos EI, Kaditis AG, Kalampouka E, et al. Nasal corticosteroids for children with snoring. Pediatr Pulmonol 2004; 38: 161-167.

144 Kheirandish L, Goldbart AD, Gozal D. Intranasal steroids and oral leukotriene modifier therapy in residual sleep-disordered breathing after tonsillectomy and adenoidectomy in children. Pediatrics 2006; 117: e61-e66.

145 Kheirandish-Gozal L, Sans Capdevila O, Kheirandish E, et al. Elevated serum aminotransferase levels in children at risk for obstructive sleep apnea. Chest 2008; 133: 92-99.

146 McLean HA, Urton AM, Driver HS, et al. Effect of treating severe nasal obstruction on the severity of obstructive sleep apnoea. Eur Respir J 2005; 25: 521-527.

147 Todorova A, Schellenberg R, Hofmann HC, et al. Effect of the external nasal dilator Breathe Right on snoring. Eur J Med Res 1998; 3: 367-379.

148 Ulfberg J, Fenton G. Effect of Breathe Right nasal strip on snoring. Rhinology 1997; 35: 50-52. 
149 Liistro G, Rombaux P, Dury M, et al. Effects of Breathe Right on snoring: a polysomnographic study. Respir Med 1998; 92: 1076-1078.

150 Wenzel M, Schonhofer B, Siemon K, et al. Nasenpflaster ohne Effekt auf die obstruktive Schlafapnoe und das Schnarchen [Nasal strips without effect on obstructive sleep apnea and snoring.] Pneumologie 1997; 51: 1108-1110.

151 Bahammam AS, Tate R, Manfreda J, et al. Upper airway resistance syndrome: effect of nasal dilation, sleep stage, and sleep position. Sleep 1999; 22: 592-598.

152 Gosepath J, Amedee RG, Romantschuck S, et al. Breathe Right nasal strips and the respiratory disturbance index in sleep related breathing disorders. Am J Rhinol 1999; 13: 385-389.

153 Lorino AM, Lofaso F, Dahan E, et al. Combined effects of a mechanical nasal dilator and a topical decongestant on nasal airflow resistance. Chest 1999; 115: 1514-1518.

154 Metes A, Cole P, Hoffstein V, et al. Nasal airway dilation and obstructed breathing in sleep. Laryngoscope 1992; 102: 1053-1055.

155 Hoffstein V, Mateika S, Metes A. Effect of nasal dilation on snoring and apneas during different stages of sleep. Sleep 1993; 16: 360-365.

156 Shinkawa A, Sakai M. A clinical study of the nasal dilator Nozovent in Japanese subjects. Tokai J Exp Clin Med 1998; 23: 13-17.

157 Hoijer U, Ejnell $\mathrm{H}$, Hedner J, et al. The effects of nasal dilation on snoring and obstructive sleep apnea. Arch Otolaryngol Head Neck Surg 1992; 118: 281-284.

158 Schonhofer B, Franklin KA, Brunig H, et al. Effect of nasalvalve dilation on obstructive sleep apnea. Chest 2000; 118: 587-590.

159 McNicholas WT, Coffey M, Boyle T. Effects of nasal airflow on breathing during sleep in normal humans. Am Rev Respir Dis 1993; 147: 620-623

160 White DP, Cadieux RJ, Lombard RM, et al. The effects of nasal anesthesia on breathing during sleep. Am Rev Respir Dis 1985; 132: 972-975.

161 Basner RC, Simon PM, Schwartzstein RM, et al. Breathing route influences upper airway muscle activity in awake normal adults. J Appl Physiol 1989; 66: 1766-1771.

162 Koutsourelakis I, Vagiakis E, Roussos C, et al. Obstructive sleep apnoea and oral breathing in patients free of nasal obstruction. Eur Respir J 2006; 28: 1222-1228.

163 Zwillich CW, Pickett C, Hanson FN, et al. Disturbed sleep and prolonged apnea during nasal obstruction in normal men. Am Rev Respir Dis 1981; 124: 158-160.

164 Lavie P, Fischel N, Zomer J, et al. The effects of partial and complete mechanical occlusion of the nasal passages on sleep structure and breathing in sleep. Acta Otolaryngol 1983; 95: 161-166.

165 Olsen KD, Kern EB, Westbrook PR. Sleep and breathing disturbance secondary to nasal obstruction. Otolaryngol Head Neck Surg 1981; 89: 804-810.

166 Rombaux P, Liistro G, Hamoir M, et al. Nocturnal oxymetry in patients with total nasal packing. Acta Otorhinolaryngol Belg 1998; 52: 223-228

167 Johannessen N, Jensen PF, Kristensen S, et al. Nasal packing and nocturnal oxygen desaturation. Acta Otolaryngol Suppl 1992; 492: 6-8.

168 Taasan V, Wynne JW, Cassisi N, et al. The effect of nasal packing on sleep-disordered breathing and nocturnal oxygen desaturation. Laryngoscope 1981; 91: 1163-1172.

169 Regli A, von Ungern-Sternberg BS, Strobel WM, et al. The impact of postoperative nasal packing on sleep-disordered breathing and nocturnal oxygen saturation in patients with obstructive sleep apnea syndrome. Anesth Analg 2006; 102: 615-620.

170 Armengot M, Hernandez R, Miguel P, et al. Effect of total nasal obstruction on nocturnal oxygen saturation. Am J Rhinol 2008; 22 325-328.
171 Morris LG, Setlur J, Burschtin OE, et al. Acoustic rhinometry predicts tolerance of nasal continuous positive airway pressure: a pilot study. Am J Rhinol 2006; 20: 133-137.

172 Koutsourelakis I, Georgoulopoulos G, Perraki E, et al. Randomised trial of nasal surgery for fixed nasal obstruction in obstructive sleep apnoea. Eur Respir J 2008; 31: 110-117.

173 Rubin AH, Eliaschar I, Joachim Z, et al. Effects of nasal surgery and tonsillectomy on sleep apnea. Bull Eur Physiopathol Respir 1983; 19: 612-615.

174 Caldarelli DD, Cartwright RD, Lilie JK. Obstructive sleep apnea: variations in surgical management. Laryngoscope 1985; 95: 1070-1073.

175 Dayal VS, Phillipson EA. Nasal surgery in the management of sleep apnea. Ann Otol Rhinol Laryngol 1985; 94: 550-554.

176 Series F, St Pierre S, Carrier G. Effects of surgical correction of nasal obstruction in the treatment of obstructive sleep apnea. Am Rev Respir Dis 1992; 146: 1261-1265.

177 Series F, St Pierre S, Carrier G. Surgical correction of nasal obstruction in the treatment of mild sleep apnoea: importance of cephalometry in predicting outcome. Thorax 1993; 48: 360-363.

178 Friedman M, Tanyeri H, Lim JW, et al. Effect of improved nasal breathing on obstructive sleep apnea. Otolaryngol Head Neck Surg 2000; 122: 71-74.

179 Verse T, Maurer JT, Pirsig W. Effect of nasal surgery on sleeprelated breathing disorders. Laryngoscope 2002; 112: 64-68.

180 Kalam I. Objective assessment of nasal obstruction in snoring and obstructive sleep apnea patients: experience of a Police Authority Hospital. Ann Saudi Med 2002; 22: 158-162.

181 Kim ST, Choi JH, Jeon HG, et al. Polysomnographic effects of nasal surgery for snoring and obstructive sleep apnea. Acta Otolaryngol 2004; 124: 297-300.

182 Nakata S, Noda A, Yagi H, et al. Nasal resistance for determinant factor of nasal surgery in CPAP failure patients with obstructive sleep apnea syndrome. Rhinology 2005; 43: 296-299.

183 Virkkula P, Bachour A, Hytonen M, et al. Snoring is not relieved by nasal surgery despite improvement in nasal resistance. Chest 2006; 129: 81-87.

184 Zonato AI, Bittencourt LR, Martinho FL, et al. Association of systematic head and neck physical examination with severity of obstructive sleep apnea-hypopnea syndrome. Laryngoscope 2003; 113: 973-980.

185 Friedman M, Tanyeri H, La Rosa M, et al. Clinical predictors of obstructive sleep apnea. Laryngoscope 1999; 109: 1901-1907.

186 Martinho FL, Zonato AI, Bittencourt LR, et al. Obese obstructive sleep apnea patients with tonsil hypertrophy submitted to tonsillectomy. Braz J Med Biol Res 2006; 39: 1137-1142.

187 Nakata S, Miyazaki S, Ohki M, et al. Reduced nasal resistance after simple tonsillectomy in patients with obstructive sleep apnea. Am J Rhinol 2007; 21: 192-195.

188 Stradling JR, Thomas G, Warley AR, et al. Effect of adenotonsillectomy on nocturnal hypoxaemia, sleep disturbance, and symptoms in snoring children. Lancet 1990; 335: 249-253.

189 Bar A, Tarasiuk A, Segev Y, et al. The effect of adenotonsillectomy on serum insulin-like growth factor-I and growth in children with obstructive sleep apnea syndrome. J Pediatr 1999; 135: 76-80.

190 Gozal D, Kheirandish-Gozal L, Serpero LD, et al. Obstructive sleep apnea and endothelial function in school-aged nonobese children: effect of adenotonsillectomy. Circulation 2007; 116: 2307-2314.

191 Tauman R, Gulliver TE, Krishna J, et al. Persistence of obstructive sleep apnea syndrome in children after adenotonsillectomy. J Pediatr 2006; 149: 803-808.

192 Schechter MS. Technical report: diagnosis and management of childhood obstructive sleep apnea syndrome. Pediatrics 2002; 109: e69. 
193 Nelson LM. Radiofrequency treatment for obstructive tonsillar hypertrophy. Arch Otolaryngol Head Neck Surg 2000; 126: 736-740.

194 Nelson LM. Temperature-controlled radiofrequency tonsil reduction: extended follow-up. Otolaryngol Head Neck Surg 2001; 125: 456-461.

195 Friedman M, LoSavio P, Ibrahim H, et al. Radiofrequency tonsil reduction: safety, morbidity, and efficacy. Laryngoscope 2003; 113: 882-887.

196 Ericsson E, Hultcrantz E. Tonsil surgery in youths: good results with a less invasive method. Laryngoscope 2007; 117: 654-661.

197 Won CH, Li KK, Guilleminault C. Surgical treatment of obstructive sleep apnea: upper airway and maxillomandibular surgery. Proc Am Thorac Soc 2008; 5: 193-199.

198 Sher AE. Upper airway surgery for obstructive sleep apnea. Sleep Med Rev 2002; 6: 195-212.

199 Tucker Woodson B. Structural effectiveness of pharyngeal sleep apnea surgery. Sleep Med Rev 2008; 12: 463-479.

200 Li HY, Wang PC, Lee LA, et al. Prediction of uvulopalatopharyngoplasty outcome: anatomy-based staging system versus severity-based staging system. Sleep 2006; 29: 1537-1541.

201 Langin T, Pepin JL, Pendlebury S, et al. Upper airway changes in snorers and mild sleep apnea sufferers after uvulopalatopharyngoplasty (UPPP). Chest 1998; 113: 1595-1603.

202 Sher AE, Schechtman KB, Piccirillo JF. The efficacy of surgical modifications of the upper airway in adults with obstructive sleep apnea syndrome. Sleep 1996; 19: 156-177.

203 Friedman M, Ibrahim H, Bass L. Clinical staging for sleepdisordered breathing. Otolaryngol Head Neck Surg 2002; 127: 13-21.

204 Hoffstein V. Review of oral appliances for treatment of sleepdisordered breathing. Sleep Breath 2007; 11: 1-22.

205 Cahali MB, Formigoni GG, Gebrim EM, et al. Lateral pharyngoplasty versus uvulopalatopharyngoplasty: a clinical, polysomnographic and computed tomography measurement comparison. Sleep 2004; 27: 942-950.

206 Shin SH, Ye MK, Kim CG. Modified uvulopalatopharyngoplasty for the treatment of obstructive sleep apnea-hypopnea syndrome: resection of the musculus uvulae. Otolaryngol Head Neck Surg 2009; 140: 924-929.

207 Walker-Engstrom ML, Wilhelmsson B, Tegelberg A, et al. Quality of life assessment of treatment with dental appliance or UPPP in patients with mild to moderate obstructive sleep apnoea. A prospective randomized 1-year follow-up study. J Sleep Res 2000; 9: 303-308.

208 Kinoshita H, Shibano A, Sakoda T, et al. Uvulopalatopharyngoplasty decreases levels of C-reactive protein in patients with obstructive sleep apnea syndrome. Am Heart J 2006; 152: 692 e1-e5.

209 Lee MY, Lin CC, Lee KS, et al. Effect of uvulopalatopharyngoplasty on endothelial function in obstructive sleep apnea. Otolaryngol Head Neck Surg 2009; 140: 369-374.

210 Kezirian EJ, Weaver EM, Yueh B, et al. Incidence of serious complications after uvulopalatopharyngoplasty. Laryngoscope 2004; 114: 450-453.

211 Franklin KA, Anttila H, Axelsson S, et al. Effects and side-effects of surgery for snoring and obstructive sleep apnea-a systematic review. Sleep 2009; 32: 27-36.

212 Janson C, Noges E, Svedberg-Randt S, et al. What characterizes patients who are unable to tolerate continuous positive airway pressure (CPAP) treatment? Respir Med 2000; 94: 145-149.

213 Ferguson KA, Heighway K, Ruby RR. A randomized trial of laser-assisted uvulopalatoplasty in the treatment of mild obstructive sleep apnea. Am J Respir Crit Care Med 2003; 167: 15-19.

214 Larrosa F, Hernandez L, Morello A, et al. Laser-assisted uvulopalatoplasty for snoring: does it meet the expectations? Eur Respir J 2004; 24: 66-70.
215 Wedman J, Miljeteig H. Treatment of simple snoring using radio waves for ablation of uvula and soft palate: a day-case surgery procedure. Laryngoscope 2002; 112: 1256-1259.

216 Lim DJ, Kang SH, Kim BH, et al. Treatment of primary snoring using radiofrequency-assisted uvulopalatoplasty. Eur Arch Otorhinolaryngol 2007; 264: 761-767.

217 Bassiouny A, El Salamawy A, Abd El-Tawab M, et al. Bipolar radiofrequency treatment for snoring with mild to moderate sleep apnea: a comparative study between the radiofrequency assisted uvulopalatoplasty technique and the channeling technique. Eur Arch Otorhinolaryngol 2007; 264: 659-667.

218 Baisch A, Maurer JT, Hormann K, et al. Combined radiofrequency assisted uvulopalatoplasty in the treatment of snoring. Eur Arch Otorhinolaryngol 2009; 266: 125-130.

219 Farrar J, Ryan J, Oliver E, et al. Radiofrequency ablation for the treatment of obstructive sleep apnea: a meta-analysis. Laryngoscope 2008; 118: 1878-1883.

220 Tvinnereim M, Mitic S, Hansen RK. Plasma radiofrequency preceded by pressure recording enhances success for treating sleep-related breathing disorders. Laryngoscope 2007; 117: 731-736.

221 Back L, Palomaki M, Piilonen A, et al. Sleep-disordered breathing: radiofrequency thermal ablation is a promising new treatment possibility. Laryngoscope 2001; 111: 464-471.

222 Terris DJ, Coker JF, Thomas AJ, et al. Preliminary findings from a prospective, randomized trial of two palatal operations for sleepdisordered breathing. Otolaryngol Head Neck Surg 2002; 127 315-323.

223 Powell NB, Riley RW, Troell RJ, et al. Radiofrequency volumetric tissue reduction of the palate in subjects with sleep-disordered breathing. Chest 1998; 113: 1163-1174.

224 Coleman SC, Smith TL. Midline radiofrequency tissue reduction of the palate for bothersome snoring and sleep-disordered breathing: a clinical trial. Otolaryngol Head Neck Surg 2000; 122: 387-394

225 Tatla T, Sandhu G, Croft CB, et al. Celon radiofrequency thermoablative palatoplasty for snoring - a pilot study. J Laryngol Otol 2003; 117: 801-806.

226 Brown DJ, Kerr P, Kryger M. Radiofrequency tissue reduction of the palate in patients with moderate sleep-disordered breathing. J Otolaryngol 2001; 30: 193-198.

227 Blumen MB, Dahan S, Fleury B, et al. Radiofrequency ablation for the treatment of mild to moderate obstructive sleep apnea. Laryngoscope 2002; 112: 2086-2092.

228 Back LJ, Liukko T, Rantanen I, et al. Radiofrequency surgery of the soft palate in the treatment of mild obstructive sleep apnea is not effective as a single-stage procedure: a randomized single-blinded placebo-controlled trial. Laryngoscope 2009; 119: 1621-1627.

229 Pazos G, Mair EA. Complications of radiofrequency ablation in the treatment of sleep-disordered breathing. Otolaryngol Head Neck Surg 2001; 125: 462-466.

230 Boudewyns A, Van De Heyning P. Temperature-controlled radiofrequency tissue volume reduction of the soft palate (somnoplasty) in the treatment of habitual snoring: results of a European multicenter trial. Acta Otolaryngol 2000; 120: 981-985.

231 Sher AE, Flexon PB, Hillman D, et al. Temperature-controlled radiofrequency tissue volume reduction in the human soft palate. Otolaryngol Head Neck Surg 2001; 125: 312-318.

232 Stuck BA, Starzak K, Verse T, et al. Complications of temperature-controlled radiofrequency volumetric tissue reduction for sleep-disordered breathing. Acta Otolaryngol 2003; 123: 532-535.

233 Kezirian EJ, Powell NB, Riley RW, et al. Incidence of complications in radiofrequency treatment of the upper airway. Laryngoscope 2005; 115: 1298-1304. 
234 Emery BE, Flexon PB. Radiofrequency volumetric tissue reduction of the soft palate: a new treatment for snoring. Laryngoscope 2000; 110: 1092-1098.

235 Ferguson M, Smith TL, Zanation AM, et al. Radiofrequency tissue volume reduction: multilesion $v$ s single-lesion treatments for snoring. Arch Otolaryngol Head Neck Surg 2001; 127: 11131118.

236 Cartwright R, Venkatesan TK, Caldarelli D, et al. Treatments for snoring: a comparison of somnoplasty and an oral appliance. Laryngoscope 2000; 110: 1680-1683.

237 Troell RJ, Powell NB, Riley RW, et al. Comparison of postoperative pain between laser-assisted uvulopalatoplasty, uvulopalatopharyngoplasty, and radiofrequency volumetric tissue reduction of the palate. Otolaryngol Head Neck Surg 2000; 122 402-409.

238 Rombaux P, Hamoir M, Bertrand B, et al. Postoperative pain and side effects after uvulopalatopharyngoplasty, laser-assisted uvulopalatoplasty, and radiofrequency tissue volume reduction in primary snoring. Laryngoscope 2003; 113: 2169-2173.

239 Blumen MB, Dahan S, Wagner I, et al. Radiofrequency versus LAUP for the treatment of snoring. Otolaryngol Head Neck Surg 2002; 126: 67-73.

240 Powell N, Riley R, Guilleminault C, et al. A reversible uvulopalatal flap for snoring and sleep apnea syndrome. Sleep 1996; 19: 593-599.

241 Neruntarat C. Uvulopalatal flap for snoring on an outpatient basis. Otolaryngol Head Neck Surg 2003; 129: 353-359.

242 Neruntarat C. Genioglossus advancement and hyoid myotomy under local anesthesia. Otolaryngol Head Neck Surg 2003; 129: 85-91.

243 Neruntarat C. Hyoid myotomy with suspension under local anesthesia for obstructive sleep apnea syndrome. Eur Arch Otorhinolaryngol 2003; 260: 286-290.

$244 \mathrm{Li} \mathrm{HY,} \mathrm{Li} \mathrm{KK,} \mathrm{Chen} \mathrm{NH,} \mathrm{et} \mathrm{al.} \mathrm{Three-dimensional} \mathrm{computed}$ tomography and polysomnography findings after extended uvulopalatal flap surgery for obstructive sleep apnea. Am J Otolaryngol 2005; 26: 7-11.

245 Li HY, Huang YS, Chen NH, et al. Mood improvement after surgery for obstructive sleep apnea. Laryngoscope 2004; 114: 10981102.

246 Li HY, Chen NH, Shu YH, et al. Changes in quality of life and respiratory disturbance after extended uvulopalatal flap surgery in patients with obstructive sleep apnea. Arch Otolaryngol Head Neck Surg 2004; 130: 195-200.

247 Li HY, Chen NH, Lee LA, et al. Use of morphological indicators to predict outcomes of palatopharyngeal surgery in patients with obstructive sleep apnea. ORL J Otorhinolaryngol Relat Spec 2004; 66: $119-123$

248 Li HY, Li KK, Chen NH, et al. Modified uvulopalatopharyngoplasty: the extended uvulopalatal flap. Am J Otolaryngol 2003; 24: 311-316.

249 Ho WK, Wei WI, Chung KF. Managing disturbing snoring with palatal implants: a pilot study. Arch Otolaryngol Head Neck Surg 2004; 130: 753-758.

250 Friedman M, Schalch P, Lin HC, et al. Palatal implants for the treatment of snoring and obstructive sleep apnea/hypopnea syndrome. Otolaryngol Head Neck Surg 2008; 138: 209-216.

251 Nordgard S, Hein G, Stene BK, et al. One-year results: palatal implants for the treatment of obstructive sleep apnea. Otolaryngol Head Neck Surg 2007; 136: 818-822.

252 Friedman M, Schalch P, Joseph NJ. Palatal stiffening after failed uvulopalatopharyngoplasty with the Pillar Implant System. Laryngoscope 2006; 116: 1956-1961.

253 Walker RP, Levine HL, Hopp ML, et al. Palatal implants: a new approach for the treatment of obstructive sleep apnea. Otolaryngol Head Neck Surg 2006; 135: 549-554.
254 Walker RP, Levine HL, Hopp ML, et al. Extended follow-up of palatal implants for OSA treatment. Otolaryngol Head Neck Surg 2007; 137: 822-827.

255 Steward DL, Huntley TC, Woodson BT, et al. Palate implants for obstructive sleep apnea: multi-institution, randomized, placebocontrolled study. Otolaryngol Head Neck Surg 2008; 139: 506-510.

256 Nordgard S, Stene BK, Skjostad KW. Soft palate implants for the treatment of mild to moderate obstructive sleep apnea. Otolaryngol Head Neck Surg 2006; 134: 565-570.

257 Maurer JT, Hein G, Verse T, et al. Long-term results of palatal implants for primary snoring. Otolaryngol Head Neck Surg 2005; 133: 573-578.

258 Nordgard S, Stene BK, Skjostad KW, et al. Palatal implants for the treatment of snoring: long-term results. Otolaryngol Head Neck Surg 2006; 134: 558-564.

259 Romanow JH, Catalano PJ. Initial U.S. pilot study: palatal implants for the treatment of snoring. Otolaryngol Head Neck Surg 2006; 134: 551-557.

260 Skjostad KW, Stene BK, Norgard S. Consequences of increased rigidity in palatal implants for snoring: a randomized controlled study. Otolaryngol Head Neck Surg 2006; 134: 63-66.

261 Woodson BT, Steward DL, Weaver EM, et al. A randomized trial of temperature-controlled radiofrequency, continuous positive airway pressure, and placebo for obstructive sleep apnea syndrome. Otolaryngol Head Neck Surg 2003; 128: 848-861.

262 Powell NB, Riley RW, Guilleminault C. Radiofrequency tongue base reduction in sleep-disordered breathing: a pilot study. Otolaryngol Head Neck Surg 1999; 120: 656-664.

263 Stuck BA, Maurer JT, Verse T, et al. Tongue base reduction with temperature-controlled radiofrequency volumetric tissue reduction for treatment of obstructive sleep apnea syndrome. Acta Otolaryngol 2002; 122: 531-536.

264 Li KK, Powell NB, Riley RW, et al. Temperature-controlled radiofrequency tongue base reduction for sleep-disordered breathing: long-term outcomes. Otolaryngol Head Neck Surg 2002; 127: 230-234

265 Steward DL, Weaver EM, Woodson BT. Multilevel temperaturecontrolled radiofrequency for obstructive sleep apnea: extended follow-up. Otolaryngol Head Neck Surg 2005; 132: 630-635.

266 Steward DL. Effectiveness of multilevel (tongue and palate) radiofrequency tissue ablation for patients with obstructive sleep apnea syndrome. Laryngoscope 2004; 114: 2073-2084.

267 Stuck BA, Starzak K, Hein G, et al. Combined radiofrequency surgery of the tongue base and soft palate in obstructive sleep apnoea. Acta Otolaryngol 2004; 124: 827-832.

268 Riley RW, Powell NB, Li KK, et al. An adjunctive method of radiofrequency volumetric tissue reduction of the tongue for OSAS. Otolaryngol Head Neck Surg 2003; 129: 37-42.

269 Toh ST, Hsu PP, Ng YH, et al. Incidence of complications after temperature-controlled radiofrequency treatment for sleepdisordered breathing: a Singapore sleep centre experience. J Laryngol Otol 2008; 122: 490-494.

270 Nelson LM, Barrera JE. High energy single session radiofrequency tongue treatment in obstructive sleep apnea surgery. Otolaryngol Head Neck Surg 2007; 137: 883-888.

271 Woodson BT, Nelson L, Mickelson S, et al. A multi-institutional study of radiofrequency volumetric tissue reduction for OSAS Otolaryngol Head Neck Surg 2001; 125: 303-311.

272 Friedman M, Lin HC, Gurpinar B, et al. Minimally invasive single-stage multilevel treatment for obstructive sleep apnea/ hypopnea syndrome. Laryngoscope 2007; 117: 1859-1863.

273 Jacobowitz O. Palatal and tongue base surgery for surgical treatment of obstructive sleep apnea: a prospective study. Otolaryngol Head Neck Surg 2006; 135: 258-264.

274 Verse T, Baisch A, Maurer JT, et al. Multilevel surgery for obstructive sleep apnea: short-term results. Otolaryngol Head Neck Surg 2006; 134: 571-577. 
275 Friedman M, Ibrahim H, Lee G, et al. Combined uvulopalatopharyngoplasty and radiofrequency tongue base reduction for treatment of obstructive sleep apnea/hypopnea syndrome. Otolaryngol Head Neck Surg 2003; 129: 611-621.

276 Fischer Y, Khan M, Mann WJ. Multilevel temperature-controlled radiofrequency therapy of soft palate, base of tongue, and tonsils in adults with obstructive sleep apnea. Laryngoscope 2003; 113: 1786-1791.

277 Nelson LM. Combined temperature-controlled radiofrequency tongue reduction and UPPP in apnea surgery. Ear Nose Throat $J$ 2001; 80: 640-644.

278 den Herder C, van Tinteren H, de Vries N. Hyoidthyroidpexia: a surgical treatment for sleep apnea syndrome. Laryngoscope 2005; 115: 740-745.

279 Riley RW, Powell NB, Guilleminault C. Obstructive sleep apnea and the hyoid: a revised surgical procedure. Otolaryngol Head Neck Surg 1994; 111: 717-721.

280 Stuck BA, Neff W, Hormann K, et al. Anatomic changes after hyoid suspension for obstructive sleep apnea: an MRI study. Otolaryngol Head Neck Surg 2005; 133: 397-402.

281 Baisch A, Maurer JT, Hormann K. The effect of hyoid suspension in a multilevel surgery concept for obstructive sleep apnea. Otolaryngol Head Neck Surg 2006; 134: 856-861.

282 Yin SK, Yi HL, Lu WY, et al. Genioglossus advancement and hyoid suspension plus uvulopalatopharyngoplasty for severe OSAHS. Otolaryngol Head Neck Surg 2007; 136: 626-631.

283 Fujita S, Woodson BT, Clark JL, et al. Laser midline glossectomy as a treatment for obstructive sleep apnea. Laryngoscope 1991; 101: 805-809.

284 Mickelson SA, Rosenthal L. Midline glossectomy and epiglottidectomy for obstructive sleep apnea syndrome. Laryngoscope 1997; 107: 614-619.

285 Andsberg U, Jessen M. Eight years of follow-up-uvulopalatopharyngoplasty combined with midline glossectomy as a treatment for obstructive sleep apnoea syndrome. Acta Otolaryngol Suppl 2000; 543: 175-178.

286 Chabolle F, Wagner I, Blumen MB, et al. Tongue base reduction with hyoepiglottoplasty: a treatment for severe obstructive sleep apnea. Laryngoscope 1999; 109: 1273-1280.

287 Sorrenti G, Piccin O, Mondini S, et al. One-phase management of severe obstructive sleep apnea: tongue base reduction with hyoepiglottoplasty plus uvulopalatopharyngoplasty. Otolaryngol Head Neck Surg 2006; 135: 906-910.

288 Woodson BT, Fujita S. Clinical experience with lingualplasty as part of the treatment of severe obstructive sleep apnea. Otolaryngol Head Neck Surg 1992; 107: 40-48.

289 Li HY, Wang PC, Hsu CY, et al. Same-stage palatopharyngeal and hypopharyngeal surgery for severe obstructive sleep apnea. Acta Otolaryngol 2004; 124: 820-826.

290 Djupesland G, Lyberg T, Krogstad O. Cephalometric analysis and surgical treatment of patients with obstructive sleep apnea syndrome. A preliminary report. Acta Otolaryngol 1987; 103: 551-557.

291 Djupesland G, Schrader H, Lyberg T, et al. Palatopharyngoglossoplasty in the treatment of patients with obstructive sleep apnea syndrome. Acta Otolaryngol Suppl 1992; 492: 50-54.

292 Miljeteig H, Tvinnereim M. Uvulopalatopharyngoglossoplasty (UPPGP) in the treatment of the obstructive sleep apnea syndrome. Acta Otolaryngol Suppl 1992; 492: 86-89.

293 Faye-Lund H, Djupesland G, Lyberg T. Glossopexia-evaluation of a new surgical method for treating obstructive sleep apnea syndrome. Acta Otolaryngol Suppl 1992; 492: 46-49.

294 DeRowe A, Gunther E, Fibbi A, et al. Tongue-base suspension with a soft tissue-to-bone anchor for obstructive sleep apnea: preliminary clinical results of a new minimally invasive technique. Otolaryngol Head Neck Surg 2000; 122: 100-103.
295 Thomas AJ, Chavoya M, Terris DJ. Preliminary findings from a prospective, randomized trial of two tongue-base surgeries for sleep-disordered breathing. Otolaryngol Head Neck Surg 2003; 129: 539-546.

296 Miller FR, Watson D, Malis D. Role of the tongue base suspension suture with The Repose System bone screw in the multilevel surgical management of obstructive sleep apnea. Otolaryngol Head Neck Surg 2002; 126: 392-398.

297 Terris DJ, Kunda LD, Gonella MC. Minimally invasive tongue base surgery for obstructive sleep apnoea. J Laryngol Otol 2002; 116: 716-721.

298 Sorrenti G, Piccin O, Latini G, et al. Tongue base suspension technique in obstructive sleep apnea: personal experience. Acta Otorhinolaryngol Ital 2003; 23: 274-280.

299 Vicente E, Marin JM, Carrizo S, et al. Tongue-base suspension in conjunction with uvulopalatopharyngoplasty for treatment of severe obstructive sleep apnea: long-term follow-up results. Laryngoscope 2006; 116: 1223-1227.

300 Kühnel TS, Schurr C, Wagner B, et al. Morphological changes of the posterior airway space after tongue base suspension. Laryngoscope 2005; 115: 475-480.

301 Omur M, Ozturan D, Elez F, et al. Tongue base suspension combined with UPPP in severe OSA patients. Otolaryngol Head Neck Surg 2005; 133: 218-223.

302 Woodson BT, Derowe A, Hawke M, et al. Pharyngeal suspension suture with repose bone screw for obstructive sleep apnea. Otolaryngol Head Neck Surg 2000; 122: 395-401.

303 Santos Junior JF, Abrahao M, Gregorio LC, et al. Genioplasty for genioglossus muscle advancement in patients with obstructive sleep apnea-hypopnea syndrome and mandibular retrognathia. Braz J Otorhinolaryngol 2007; 73: 480-486.

304 Kezirian EJ, Goldberg AN. Hypopharyngeal surgery in obstructive sleep apnea: an evidence-based medicine review. Arch Otolaryngol Head Neck Surg 2006; 132: 206-213.

305 Riley RW, Powell NB, Guilleminault C. Maxillofacial surgery and obstructive sleep apnea: a review of 80 patients. Otolaryngol Head Neck Surg 1989; 101: 353-361.

306 Hochban W, Brandenburg U, Peter JH. Surgical treatment of obstructive sleep apnea by maxillomandibular advancement. Sleep 1994; 17: 624-629.

307 Prinsell JR. Maxillomandibular advancement surgery in a sitespecific treatment approach for obstructive sleep apnea in 50 consecutive patients. Chest 1999; 116: 1519-1529.

308 Bettega G, Pepin JL, Veale D, et al. Obstructive sleep apnea syndrome. Fifty-one consecutive patients treated by maxillofacial surgery. Am J Respir Crit Care Med 2000; 162: 641-649.

309 Dekeister C, Lacassagne L, Tiberge M, et al. Prise en charge par chirurgie d'avancée des maxillaires des patients porteurs d'un syndrome d'apnées du sommeil sévère en échec d'un traitement par pression positive continue: étude rétrospective de 25 patients entre 1998 et 2004. [Mandibular advancement surgery in patients with severe obstructive sleep apnea uncontrolled by continuous positive airway pressure. A retrospective review of 25 patients between 1998 and 2004.] Rev Mal Respir 2006; 23 430-437.

310 Waite PD, Wooten V, Lachner J, et al. Maxillomandibular advancement surgery in 23 patients with obstructive sleep apnea syndrome. J Oral Maxillofac Surg 1989; 47: 1256-1261.

$311 \mathrm{Li} \mathrm{KK}$, Powell NB, Riley RW, et al. Long-term results of maxillomandibular advancement surgery. Sleep Breath 2000; 4: 137-140

312 Wagner I, Coiffier T, Sequert C, et al. Traitement chirurgical du syndrome d'apnées du sommeil sévère par avancée maxillomandibulaire ou par transposition génienne. [Surgical treatment of severe sleep apnea syndrome by maxillomandibular advancing or mental tranposition.] Ann Otolaryngol Chir Cervicofac 2000; 117: 137-146. 
313 Dattilo DJ, Drooger SA. Outcome assessment of patients undergoing maxillofacial procedures for the treatment of sleep apnea: comparison of subjective and objective results. J Oral Maxillofac Surg 2004; 62: 164-168.

314 Goh YH, Lim KA. Modified maxillomandibular advancement for the treatment of obstructive sleep apnea: a preliminary report. Laryngoscope 2003; 113: 1577-1582.

315 Smatt Y, Ferri J. Retrospective study of 18 patients treated by maxillomandibular advancement with adjunctive procedures for obstructive sleep apnea syndrome. J Craniofac Surg 2005; 16 : 770-777.

316 Hendler BH, Costello BJ, Silverstein K, et al. A protocol for uvulopalatopharyngoplasty, mortised genioplasty, and maxillomandibular advancement in patients with obstructive sleep apnea: an analysis of 40 cases. J Oral Maxillofac Surg 2001; 59: 892-897.

317 Paoli JR, Lauwers F, Lacassagne L, et al. Treatment of obstructive sleep apnea syndrome by mandibular elongation using osseous distraction followed by a Le Fort I advancement osteotomy: case report. J Oral Maxillofac Surg 2001; 59: 216-219.

318 Guilleminault C, Quera-Salva MA, Powell NB, et al. Maxillomandibular surgery for obstructive sleep apnoea. Eur Respir J 1989; 2: 604-612.

319 Practice parameters for the indications for polysomnography and related procedures. Polysomnography Task Force, American Sleep Disorders Association Standards of Practice Committee. Sleep 1997; 20: 406-422.

320 Riley R, Guilleminault C, Herran J, et al. Cephalometric analyses and flow-volume loops in obstructive sleep apnea patients. Sleep 1983; 6: 303-311.

321 Paoli JR, Lauwers F, Lacassagne L, et al. Craniofacial differences according to the body mass index of patients with obstructive sleep apnoea syndrome: cephalometric study in 85 patients. $\mathrm{Br} J$ Oral Maxillofac Surg 2001; 39: 40-45.

322 Riley RW, Powell NB, Guilleminault C. Maxillofacial surgery and nasal CPAP. A comparison of treatment for obstructive sleep apnea syndrome. Chest 1990; 98: 1421-1425.

323 Conradt R, Hochban W, Brandenburg U, et al. Long-term followup after surgical treatment of obstructive sleep apnoea by maxillomandibular advancement. Eur Respir J 1997; 10: 123-128.

324 Nimkarn Y, Miles PG, Waite PD. Maxillomandibular advancement surgery in obstructive sleep apnea syndrome patients: longterm surgical stability. J Oral Maxillofac Surg 1995; 53: 1414-1418.

325 Pepin J-L. Obstructive Sleep Apnea: Overall Treatment Modalities and Strategy. ERS School Course, Grenoble, 2008. Course material available from: www.ers-education.org/pages/ default.aspx?id $=1378$.

326 Series F, Marc I. Nasal pressure recording in the diagnosis of sleep apnoea hypopnoea syndrome. Thorax 1999; 54: 506-510.

327 Petit FX, Pepin JL, Bettega G, et al. Mandibular advancement devices: rate of contraindications in 100 consecutive obstructive sleep apnea patients. Am J Respir Crit Care Med 2002; 166: 274-278.

328 Loadsman JA, Hillman DR. Anaesthesia and sleep apnoea. $\mathrm{Br} J$ Anaesth 2001; 86: 254-266.

329 Li KK, Riley RW, Powell NB, et al. Patient's perception of the facial appearance after maxillomandibular advancement for obstructive sleep apnea syndrome. J Oral Maxillofac Surg 2001; 59: 377-380.

330 Randerath WJ, Bauer M, Blau A, et al. Stellenwert der NichtnCPAP-Verfahren in der Therapie des obstruktiven SchlafapnoeSyndroms. [Relevance of non-CPAP treatment options in the therapy of obstructive sleep apnea syndrome.] Somnologie 2006; 10: 67-98.

331 Li KK, Riley R, Powell N. Skeletal expansion by gradual intraoral distraction osteogenesis for the treatment of obstructive sleep apnea. Head Neck Surg 2002; 13: 119-122.
332 Ow AT, Cheung LK. Meta-analysis of mandibular distraction osteogenesis: clinical applications and functional outcomes. Plast Reconstr Surg 2008; 121: 54e-69e.

333 Guilleminault C, Simmons FB, Motta J, et al. Obstructive sleep apnea syndrome and tracheostomy. Long-term follow-up experience. Arch Intern Med 1981; 141: 985-988.

334 Moore MH, Guzman-Stein G, Proudman TW, et al. Mandibular lengthening by distraction for airway obstruction in TreacherCollins syndrome. J Craniofac Surg 1994; 5: 22-25.

335 Perkins JA, Sie KC, Milczuk H, et al. Airway management in children with craniofacial anomalies. Cleft Palate Craniofac J 1997; 34: 135-140.

336 Cohen SR, Ross DA, Burstein FD, et al. Skeletal expansion combined with soft-tissue reduction in the treatment of obstructive sleep apnea in children: physiologic results. Otolaryngol Head Neck Surg 1998; 119: 476-485.

337 Cohen SR, Simms C, Burstein FD. Mandibular distraction osteogenesis in the treatment of upper airway obstruction in children with craniofacial deformities. Plast Reconstr Surg 1998; 101: 312-318.

338 Cohen SR. Craniofacial distraction with a modular internal distraction system: evolution of design and surgical techniques. Plast Reconstr Surg 1999; 103: 1592-1607.

339 Hoeve HL, Joosten KF, van den Berg S. Management of obstructive sleep apnea syndrome in children with craniofacial malformation. Int J Pediatr Otorhinolaryngol, 1999: 59-61.

340 Morovic CG, Monasterio L. Distraction osteogenesis for obstructive apneas in patients with congenital craniofacial malformations. Plast Reconstr Surg 2000; 105: 2324-2330.

341 Denny AD, Talisman R, Hanson PR, et al. Mandibular distraction osteogenesis in very young patients to correct airway obstruction. Plast Reconstr Surg 2001; 108: 302-311.

342 Uemura $\mathrm{T}$, Hayashi $\mathrm{T}$, Satoh $\mathrm{K}$, et al. A case of improved obstructive sleep apnea by distraction osteogenesis for midface hypoplasia of an infantile Crouzon's syndrome. J Craniofac Surg 2001; 12: 73-77.

343 Cohen SR, Holmes RE, Machado L, et al. Surgical strategies in the treatment of complex obstructive sleep apnoea in children Paediatr Respir Rev 2002; 3: 25-35.

344 Li KK, Powell NB, Riley RW, et al. Distraction osteogenesis in adult obstructive sleep apnea surgery: a preliminary report. J Oral Maxillofac Surg 2002; 60: 6-10.

345 Monasterio FO, Drucker M, Molina F, et al. Distraction osteogenesis in Pierre Robin sequence and related respiratory problems in children. J Craniofac Surg 2002; 13: 79-83.

346 Izadi K, Yellon R, Mandell DL, et al. Correction of upper airway obstruction in the newborn with internal mandibular distraction osteogenesis. J Craniofac Surg 2003; 14: 493-499.

347 Wang $X$, Wang XX, Liang C, et al. Distraction osteogenesis in correction of micrognathia accompanying obstructive sleep apnea syndrome. Plast Reconstr Surg 2003; 112: 1549-1557.

348 Guilleminault C, Li KK. Maxillomandibular expansion for the treatment of sleep-disordered breathing: preliminary result. Laryngoscope 2004; 114: 893-896.

349 Mandell DL, Yellon RF, Bradley JP, et al. Mandibular distraction for micrognathia and severe upper airway obstruction. Arch Otolaryngol Head Neck Surg 2004; 130: 344-348.

350 Monasterio FO, Molina F, Berlanga F, et al. Swallowing disorders in Pierre Robin sequence: its correction by distraction. J Craniofac Surg 2004; 15: 934-941.

351 Schaefer RB, Stadler JA 3rd, Gosain AK. To distract or not to distract: an algorithm for airway management in isolated Pierre Robin sequence. Plast Reconstr Surg 2004; 113: 1113-1125.

352 Wittenborn W, Panchal J, Marsh JL, et al. Neonatal distraction surgery for micrognathia reduces obstructive apnea and the need for tracheotomy. J Craniofac Surg 2004; 15: 623-630. 
353 Allen GC. Mandibular distraction osteogenesis for neonatal airway obstruction. Operative Techniques in Otolaryngology 2005; 16: 187-193.

354 Chigurupati R, Myall R. Airway management in babies with micrognathia: the case against early distraction. J Oral Maxillofac Surg 2005; 63: 1209-1215.

355 Rachmiel A, Aizenbud D, Pillar G, et al. Bilateral mandibular distraction for patients with compromised airway analyzed by three-dimensional CT. Int J Oral Maxillofac Surg 2005; 34: 9-18.

356 Steinbacher DM, Kaban LB, Troulis MJ. Mandibular advancement by distraction osteogenesis for tracheostomy-dependent children with severe micrognathia. J Oral Maxillofac Surg 2005; 63: $1072-1079$.

357 Li KK. Distraction osteogenesis and obstructive sleep apnea syndrome. Operative Techniques in Otolaryngology 2006; 17: 256-261.

358 Lin SY, Halbower AC, Tunkel DE, et al. Relief of upper airway obstruction with mandibular distraction surgery: Long-term quantitative results in young children. Arch Otolaryngol Head Neck Surg 2006; 132: 437-441.

359 Roy S, Patel PK. Mandibular lengthening in micrognathic infants with the internal distraction device. Arch Facial Plast Surg 2006; 8: 60-64.

360 Hultcrantz E. Surgical treatment of children with obstructive sleep apnea. In: Koutakis SE, Onerci TM, eds. Rhinologic and Sleep Apnea Surgical Techniques. Berlin, Springer, 2007; pp. 379-390.

361 Mitsukawa N, Satoh K, Suse $\mathrm{T}$, et al. Clinical success of mandibular distraction for obstructive sleep apnea resulting from micrognathia in 10 consecutive Japanese young children. J Craniofac Surg 2007; 18: 948-953.

362 Thompson SH, Quinn M, Helman JI, et al. Maxillomandibular distraction osteogenesis advancement for the treatment of obstructive sleep apnea. I Oral Maxillofac Surg 2007; 65: 1427-1429.

363 Dauria D, Marsh JL. Mandibular distraction osteogenesis for Pierre Robin sequence: what percentage of neonates need it? J Craniofac Surg 2008; 19: 1237-1243.

364 Bouchard C, Troulis MJ, Kaban LB. Management of obstructive sleep apnea: role of distraction osteogenesis. Oral Maxillofac Surg Clin North Am 2009; 21: 459-475.

365 Breugem CC, Mink van der Molen AB. What is "Pierre Robin sequence"? J Plast Reconstr Aesthet Surg 2009; 62: 1555-1558.

366 Butow KW, Hoogendijk CF, Zwahlen RA. Pierre Robin sequence: appearances and 25 years of experience with an innovative treatment protocol. J Pediatr Surg 2009; 44: 2112-2118

367 Genecov DG, Barcelo CR, Steinberg D, et al. Clinical experience with the application of distraction osteogenesis for airway obstruction. J Craniofac Surg 2009; 20: Suppl. 2, 1817-1821.

368 Looby JF, Schendel SA, Lorenz HP, et al. Airway analysis: with bilateral distraction of the infant mandible. J Craniofac Surg 2009; 20: 1341-1346.

369 Molina F. Mandibular distraction osteogenesis: a clinical experience of the last 17 years. J Craniofac Surg 2009; 20: Suppl. 2, 1794-1800.

370 Shen W, Jie C, Chen J, et al. Mandibular distraction osteogenesis to relieve pierre robin severe airway obstruction in neonates: indication and operation. J Craniofac Surg 2009; 20: Suppl. 2, 1812-1816
371 Benazzo M, Pagella F, Matti E, et al. Hyoidthyroidpexia as a treatment in multilevel surgery for obstructive sleep apnea. Acta Otolaryngol 2008; 128: 680-684.

372 Eun YG, Kim SW, Kwon KH, et al. Single-session radiofrequency tongue base reduction combined with uvulopalatopharyngoplasty for obstructive sleep apnea syndrome. Eur Arch Otorhinolaryngol 2008; 265: 1495-1500.

373 Eun YG, Kwon KH, Shin SY, et al. Multilevel surgery in patients with rapid eye movement-related obstructive sleep apnea. Otolaryngol Head Neck Surg 2009; 140: 536-541.

374 Richard W, Kox D, den Herder C, et al. One stage multilevel surgery (uvulopalatopharyngoplasty, hyoid suspension, radiofrequent ablation of the tongue base with/without genioglossus advancement), in obstructive sleep apnea syndrome. Eur Arch Otorhinolaryngol 2007; 264: 439-444.

375 Riley RW, Powell NB, Guilleminault C. Obstructive sleep apnea syndrome: a review of 306 consecutively treated surgical patients. Otolaryngol Head Neck Surg 1993; 108: 117-125.

376 Johnson NT, Chinn J. Uvulopalatopharyngoplasty and inferior sagittal mandibular osteotomy with genioglossus advancement for treatment of obstructive sleep apnea. Chest 1994; 105: 278-283.

377 Ramirez SG, Loube DI. Inferior sagittal osteotomy with hyoid bone suspension for obese patients with sleep apnea. Arch Otolaryngol Head Neck Surg 1996; 122: 953-957.

378 Elasfour A, Miyazaki S, Itasaka Y, et al. Evaluation of uvulopalatopharyngoplasty in treatment of obstructive sleep apnea syndrome. Acta Otolaryngol Suppl 1998; 537: 52-56.

379 Lee NR, Givens CD Jr, Wilson J, et al. Staged surgical treatment of obstructive sleep apnea syndrome: a review of 35 patients. J Oral Maxillofac Surg 1999; 57: 382-385.

380 Hsu PP, Brett RH. Multiple level pharyngeal surgery for obstructive sleep apnoea. Singapore Med J 2001; 42: 160-164.

381 Vilaseca I, Morello A, Montserrat JM, et al. Usefulness of uvulopalatopharyngoplasty with genioglossus and hyoid advancement in the treatment of obstructive sleep apnea. Arch Otolaryngol Head Neck Surg 2002; 128: 435-440.

382 Neruntarat C. Genioglossus advancement and hyoid myotomy: short-term and long-term results. J Laryngol Otol 2003; 117: 482-486.

383 Miller FR, Watson D, Boseley M. The role of the genial bone advancement trephine system in conjunction with uvulopalatopharyngoplasty in the multilevel management of obstructive sleep apnea. Otolaryngol Head Neck Surg 2004; 130: 73-79.

384 Verse T, Baisch A, Hormann K. Multi-Level-Chirurgie bei obstruktiver Schlafapnoe. Erste objektive Ergebnisse [Multi-level surgery for obstructive sleep apnea. Preliminary objective results]. Laryngorhinootologie 2004; 83: 516-522.

385 Kao YH, Shnayder Y, Lee KC. The efficacy of anatomically based multilevel surgery for obstructive sleep apnea. Otolaryngol Head Neck Surg 2003; 129: 327-335.

386 Liu SA, Li HY, Tsai WC, et al. Associated factors to predict outcomes of uvulopharyngopalatoplasty plus genioglossal advancement for obstructive sleep apnea. Laryngoscope 2005; 115: 2046-2050.

387 Bowden MT, Kezirian EJ, Utley D, et al. Outcomes of hyoid suspension for the treatment of obstructive sleep apnea. Arch Otolaryngol Head Neck Surg 2005; 131: 440-445.

388 Sundaram S, Bridgman SA, Lim J, et al. Surgery for obstructive sleep apnoea. Cochrane Database Syst Rev 2005; 4: CD001004.

389 Lin HC, Friedman M, Chang HW, et al. The efficacy of multilevel surgery of the upper airway in adults with obstructive sleep apnea/hypopnea syndrome. Laryngoscope 2008; 118: 902-908. 